\title{
Clearing the Fog: The Predictive Power of Weather for Employment Reports and their Asset Price Responses
}

\author{
Daniel J. Wilson \\ Federal Reserve Bank of San Francisco \\ September 2017 \\ Working Paper 2017-13 \\ http://www.frbsf.org/economic-research/publications/working-papers/2017/13/
}

\section{Suggested citation:}

Wilson, Daniel J. 2017. "Clearing the Fog: The Predictive Power of Weather for Employment Reports and their Asset Price Responses” Federal Reserve Bank of San Francisco Working Paper 2017-13. https://doi.org/10.24148/wp2017-13

The views in this paper are solely the responsibility of the authors and should not be interpreted as reflecting the views of the Federal Reserve Bank of San Francisco or the Board of Governors of the Federal Reserve System. 


\title{
Clearing the Fog: The Predictive Power of Weather for Employment Reports and their Asset Price Responses
}

\begin{abstract}
By DANIEL J. WILSON*
This paper exploits vast granular data - with over one million countymonth observations - to estimate a dynamic panel data model of weather's local employment effects. The fitted county model is then aggregated and used to generate in-sample and rolling out-of-sample ("nowcast") estimates of the weather effect on national monthly employment. These nowcasts, which use only employment and weather data available prior to a given employment report, are significantly predictive not only of the surprise component of employment reports but also of stock and bond market returns on the days of employment reports.
\end{abstract}

September 26, 2017

JEL Codes: Q52, R11, J21, G17

Keywords: Macroeconomic data surprises, weather, nowcasting, asset price sensitivity to macroeconomic news

*Federal Reserve Bank of San Francisco. I thank Catherine van der List, Annemarie Schweinert, and Joseph Pedtke for superb research assistance and Matthew Ranson for providing his data and code for constructing county weather measures. This paper benefitted greatly from discussions with Michael Boldin, Francois Gourio, Jim Hamilton, Bart Hobijn, Oscar Jorda, Jeffrey Lin, Eric Swanson, John Williams, Jonathan Wright, and seminar participants at the University of California, Irvine and the 2017 NBER Summer Institute "Forecasting and Empirical Methods" Workshop. The views expressed in this paper are solely the responsibility of the author and should not be interpreted as reflecting the views of the Federal Reserve Bank of San Francisco or the Federal Reserve System. 
On June 3, 2016 at 8:30am EDT, the U.S. Bureau of Labor Statistics released the May 2016 employment report. It was alarmingly bad. According to the report, seasonally-adjusted private nonfarm employment in the U.S. grew that month by only 25,000 . This was the lowest monthly gain in employment in six years and followed very strong reports over the prior three months. ${ }^{2}$ Economic analysts and financial market participants had been expecting a number around $160,000 .{ }^{3}$ The dismal report caught policymakers and financial markets off-guard and raised concern that the labor market recovery had stalled. The financial markets reacted strongly to the news, with Treasury bond yields and stock market indices falling sharply in the minutes and hours after the report's release. The 10year Treasury yield closed down 10 basis points by the end of the day.

After the release, some economic analysts noted in media reports that May had been unusually cold in most of the country. They also pointed out that weather-sensitive industries like Construction and Mining \& Logging saw unusually large declines in employment that month. Less commented upon was the fact that February and March had been unusually warm, dry, and devoid of snow in most of the nation's largest economic centers, including New England, the mid-Atlantic, and the upper Midwest. And weather-sensitive industries like Construction and Mining \& Logging had large employment gains in those months. Employment growth in these sectors and overall bounced back strongly in June. These bits of information taken together hint at the possibility that current and lagged weather had large effects on monthly employment changes during this period, with unusually favorable weather in the early spring pulling forward some economic activity that normally would take place in May. More surprisingly, they hint at the possibility that financial markets were surprised by these weather effects despite the fact that weather data are publicly available in real time and hence should be part of the markets' information set.

Of course, this is simply one episode and it is possible that weather had nothing to do with the unexpected downward blip in employment growth in May 2016. Yet, more generally, weather is often cited by the media, financial analysts, and policymakers as a key factor behind short-run fluctuations in macroeconomic data. And the role of weather in explaining such fluctuations has been welldocumented. ${ }^{4}$ A natural implication is that weather, given that it is measurable in real-time, should be

\footnotetext{
${ }^{2}$ It was subsequently revised down to 17,000 , making it the worst month of employment growth since February 2010, according to the current vintage of BLS employment data.

${ }^{3}$ The median forecast from the survey done by Action Economics (formerly Money Market Services) each month prior to the employment report was 154,000 . Bloomberg reported a consensus pre-report expectation from financial market participants of 160,000 .

${ }^{4}$ See Boldin and Wright (2015) and Bloesch \& Gourio (2015) regarding nonfarm payroll employment, Lazo, et al. (2011) on GDP, Starr-McCluer (2000) on retail sales, and Gilchrist and Sands (2016) on movie theater revenues.
} 
useful in predicting, or "nowcasting," contemporaneous macroeconomic data. Such predictive power obviously would be highly valuable to policymakers trying to discern the underlying strength of economic conditions as well as to financial market participants given the sensitivity of many asset prices to macroeconomic news. Surprisingly, there is little, if any, evidence one way or the other on the predictive power of real-time weather data for macroeconomic surprises and their asset price responses. This paper takes a step toward filling that void. It develops a methodology for using geographically granular real-time data to predict weather's impact on the latest month's national payroll employment growth prior to its release. These weather effect nowcasts have strong predictive power for payroll employment growth surprises - reported employment growth relative to pre-report forecasts - and equity and Treasury bond returns on the days of employment reports.

The first step of the methodology involves estimating a county-level dynamic panel data (DPD) model of monthly employment growth as a function of current and lagged values of temperature, precipitation, and snowfall. The model is estimated using employment data from BLS administrative records and daily NOAA weather-station data aggregated to a monthly frequency. The full data set covers the period January 1980 through August 2016, amounting to over 1.3 million county-month observations; the nowcasting exercise uses rolling (expanding-window) subsamples of these data to simulate real-time predictions.

The combination of high-frequency and finely geographically-disaggregated data used in estimating the county DPD models offers considerable advantages. First, it yields precisely estimated marginal effects of each weather variable. Second, it allows for rich specifications. In particular, one can account for numerous weather variables, for lagged effects (to assess mean reversion and the permanence of weather effects), for heterogeneity in weather effects across key dimensions such as region and season, and for spatial spillovers. The vastness of the data set also allows one to control for high-dimensional fixed effects. Specifically, I include fixed effects for county*calendarmonth*decade and time (sample-month) fixed effects. The former control for county-specific seasonal patterns and the latter control for national common factors such as business cycles, oil price shocks, etc.

The estimates from the county DPD model show that contemporaneous local monthly employment growth is increasing in temperature - with the largest effect in the spring - decreasing in precipitation, and decreasing in snowfall. The estimates also indicate that the effects of temperature and snowfall are largely transitory, with near-zero cumulative effects over four months. Precipitation, on the other hand, is estimated to have a negative contemporaneous effect but a positive cumulative 
effect over four months. I also find negative contemporaneous and cumulative employment effects from the number of very hot days, where the daily high temperature is over $90^{\circ}$ Fahrenheit $(\mathrm{F})\left(32.2^{\circ}\right.$ Celsius (C)) in the month, holding mean daily high temperature fixed. The number of very cold days, where the daily low temperature is below $30^{\circ} \mathrm{F}\left(-1.1^{\circ} \mathrm{C}\right)$, has negative but insignificant contemporaneous and cumulative effects.

In the next step of the methodology, I use the fitted county DPD model to obtain estimates of weather's employment growth effects for every county in any given month. The fitted model is generated using the full sample (Jan. 1980 - Dec. 2015) for in-sample "backcasting" evaluations, and rolling (expanding-window) subsamples for out-of-sample "nowcasting" evaluations. In the last step, the county-level estimates of weather's employment effect for a given month are aggregated to obtain estimates of weather's national employment effect. Because the national effect could differ from the sum of the local effects if there are spatial spillovers, I estimate and aggregate versions of the county DPD model that include spatial lags of weather, in addition to more parsimonious models without spatial lags.

After applying this methodology to obtain national weather effect estimates, I first evaluate their in-sample and out-of-sample explanatory power for national employment growth. The out-ofsample estimated weather effects are based on a rolling out-of-sample nowcasting exercise, which only uses data that would be available to an analyst prior to the corresponding employment report. ${ }^{5}$ Other recent efforts, most notably Boldin and Wright (2015) and Bloesch and Gourio (2015), have sought to similarly estimate the real-time effects of weather on the national payroll employment growth using more aggregate data. However, the empirical models underlying their estimated national effects are much more parsimonious and less precisely estimated than the county DPD model. None of these prior studies investigated the predictive power of their estimates for employment release surprises or asset prices responses.

I find that these weather effect nowcasts have better out-of-sample explanatory power for national employment growth than nowcasts from a national time series model. Among the different versions of the county DPD model I consider - a parsimonious version without regional heterogeneity in the marginal effect of each weather variable and without spatial lags, a version with regional

\footnotetext{
${ }^{5}$ The data available to an analyst prior to a given reference month's employment report release, which typically occurs on the first Friday after the end of the reference month, are daily weather-station data through the end of the reference month, national employment data through the prior month from the BLS Current Employment Statistics (CES), and county employment data through six to eight months prior from the BLS Quarterly Census of Employment and Wages (QCEW).
} 
heterogeneity but without spatial lags, and a version without regional heterogeneity but with spatial lags - the version with regional heterogeneity yields the best in-sample and out-of-sample fit. Nonetheless, even the weather effect estimates from this model explain a relatively small fraction of the variation in national employment growth. However, I find that these national weather effects have a strong positive association with the surprise component of employment data releases, both insample and out-of-sample. Surprises are measured by the difference between the real-time reported data and the median survey forecast from market participants prior to the release. The weather effect backcasts, based on estimation of the county DPD model using the full sample, have a positive and significant association with monthly employment growth surprises and can explain roughly $8 \%$ of their time series variation. More importantly, the weather effect nowcasts, based on the rolling outof-sample estimation, also are strongly predictive of employment release surprises. The nowcasts have a positive and statistically significant effect on employment surprises and can explain about $15 \%$ of their variation.

Given this finding, I then investigate the predictive power of the weather effect nowcasts on stock market returns and Treasury yield changes on employment report release days. The nowcasts have surprisingly strong predictive power for both stock market returns and Treasury yields. ${ }^{6}$ The estimates from these regressions suggest that asset markets do not fully account for weather's effects on macroeconomic data.

To illustrate the magnitude of weather's importance for explaining asset price movements on employment report days, I estimate the returns, Sharpe ratios and success rates, for equities and Treasury bonds, from a simple long-short trading strategy based on the sign of the weather effect nowcast. For both stocks and bonds, the weather nowcast correctly predicts the sign of the daily return about $60 \%$ of the time. For stocks, the trading strategy yields a Sharpe ratio around 0.6 and a cumulative annualized return (in excess of any investment returns on non-employment report days) of about $2.1 \%$. For Treasury bonds, the results vary by maturity length, with Sharpe ratios as high as 1.0 and cumulative returns as high as $4.5 \%$.

\footnotetext{
${ }^{6}$ Most prior work on the relationship between weather and asset prices has focused on the effect of weather on the mood of market participants and, in turn, market returns on days of favorable or unfavorable weather. For instance, Saunders (1993), Hirshleifer \& Shumway (2003), and Goetzmann, et al. (2014) find that daily stock market returns are significantly affected by the degree of cloudiness on that day in the city in which the stock market exchange is located. Busse, et al. (2014) find similar psychological weather effects on auto purchases.
} 


\section{Data}

\section{A. Employment and Other Outcomes}

Data on employment by county, industry, and month are available from the Quarterly Census of Employment and Wages (QCEW). ${ }^{7}$ As of the time of this writing, the QCEW data for NAICS industries are available from January 1990 through December 2015. Data for SIC industries is available from January 1975 through December 2000. The QCEW is compiled by the Bureau of Labor Statistics based on state Unemployment Insurance administrative records. Nearly all private nonfarm employers in the U.S. are required to report monthly employment counts and quarterly total wages of their employees to their state's Unemployment Insurance agency. Employment covers "all full- and part-time workers who worked during or received pay (subject to Unemployment Insurance wages) for the pay period which includes the 12th day of the month." ${ }^{\prime 8}$ Note that this is the same definition of employment used in the payroll survey underlying the monthly national payroll employment report (i.e., the BLS Current Employment Statistics (CES) report). ${ }^{9}$

The CES payroll survey does not cover agriculture, ranching, fishing, and hunting, which are included in the QCEW's all-industry employment total. Thus, to ensure full comparability between the CES and QCEW industry coverage, I construct an alternative QCEW "all-industry" sample that excludes these subsectors (which are a very small fraction of QCEW total employment).

I measure monthly surprises to total nonfarm employment growth by the difference between actual, real-time (as first reported) employment growth and the median forecast of employment growth from a survey of economists and market participants conducted in the few days prior to the employment report. The survey and real-time data, from January 1990 to present, come from Money Market Services (MMS)/Action Economics and have been used previously in event studies of the financial market responses to macroeconomic data releases (see, e.g., Gurkaynak, Sachs, and Swanson 2005)..$^{10}$ Daily data (close-of-market) data on the Dow-Jones Industrial price index, S\&P 500 price index, and Treasury bond yields were pulled from the FAME database.

\footnotetext{
${ }^{7} \mathrm{http://www.bls.gov/cew/datatoc.htm}$.

8 http://www.bls.gov/cew/cewproper.htm.

9 http://www.bls.gov/web/empsit/cesfaq.htm\#qc2.

${ }^{10}$ Unfortunately, the survey did not begin separately asking about private nonfarm employment until late 2011 . Hence, I use total nonfarm employment here.
} 


\section{B. Weather}

I construct data on weather by county and month from the Global Historical Climatology Network Daily (GHCN-Daily) data set. The GHCN-Daily is a product of the U.S. National Climatic Data Center (part of the National Oceanic and Atmospheric Administration (NOAA)) and contains daily weather measurements from weather stations throughout the United States and around the world. ${ }^{11}$ Using these records from individual weather stations, I measure county-level weather as follows. ${ }^{12}$ First, the surface of the conterminous United States is divided into a 5-mile by 5-mile grid. Second, weather values for each grid point are estimated using inverse-distance-weighted averages of the weather values from weather stations within 50 miles of the grid point. These county-level daily weather measures are used to construct monthly variables.

As noted above, both the CES and QCEW aim to measure the number of individuals on employer payrolls as of the pay period containing the $12^{\text {th }}$ of the month. This suggests that for a given firm, weather during the pay period containing the $12^{\text {th }}$ of the month will matter much more than weather on other days for the employment counts that they report to the BLS. Thus, aggregating over firms, the most relevant set of weather days depends on the distribution of pay period frequencies. The BLS reports that about one-third of businesses pay weekly and nearly $20 \%$ pay semimonthly (i.e., pay periods for the first half of the month and second half of the month)(Burgess 2014). Thus, for a little over half of employers, weather on days beyond the first two is largely irrelevant. Another $37 \%$ of businesses pay biweekly, for which weather during the two weeks including the $12^{\text {th }}$ matters most. Only a small share of employers pay monthly, for which all weeks of the month are relevant.

To assess more formally which weeks of weather are most relevant for reported employment counts, I estimate a variant of the panel fixed effects regression discussed in more detail in Section II. In this variant, I regress monthly county employment growth on weather variables for each of the weeks within the month (where the fourth "week" is day 22 through the end of the month). The weekly weather variables are average daily-high temperature, average daily precipitation, and average daily snowfall. The regressions include fixed effects for time (sample-month) and county-bycalendar-month-by-decade to absorb county-specific, decade-varying seasonality.

The results are shown in Table 1. Though the exact pattern of effects over the four weeks varies somewhat by variable, the impact of weather in the first two weeks of the month tends to be

\footnotetext{
${ }^{11} \mathrm{http}: / /$ www.ncdc.noaa.gov/oa/climate/ghen-daily/.

${ }^{12}$ See Wilson (2017) for further details on the construction of the county-month weather data. The approach broadly follows that of Ranson (2014).
} 
roughly double that of weather in the last two weeks. To be precise, the implied weights averaged over the five variables are 0.30 on week $1,0.34$ on week $2,0.15$ on week 3 , and 0.21 on week $4 .{ }^{13}$ Thus, both the distribution of pay period frequencies reported by the BLS and these empirical estimates suggest giving roughly double weight to weather in the first two weeks relative to the last two weeks when constructing monthly weather variables. For the baseline monthly weather variables used in the analyses below, weather from the first two weeks is given double weight relative to the remainder of the month in constructing the monthly variables. Alternative results based on using equal weights, zero weight on the last two weeks, or the average implied weights from Table 1 are all qualitatively similar and are available upon request. The five daily weather variables used to construct these monthly weighted averages are daily-high temperature, an indicator for whether the maximum temperature was above $90^{\circ} \mathrm{F}\left(32.2^{\circ} \mathrm{C}\right)$, an indicator for whether the minimum temperature was below $30^{\circ} \mathrm{F}\left(-1.1^{\circ} \mathrm{C}\right)$, daily precipitation, and daily snowfall.

\section{Dynamic Panel-Data Model for Local Weather Effects}

As mentioned earlier, the first step in the methodology for estimating national weather effect estimates entails estimating the effect of weather on monthly employment growth at the local level. To do so, I use a county-level dynamic panel data (DPD) model. ${ }^{14}$ The general regression specification is of the following form:

$$
\Delta l_{c t}=\gamma_{t}+\alpha_{c, m(t), d(t)}+\sum_{k=1}^{K} \sum_{j=1}^{9} \sum_{i=1}^{4} \sum_{\tau=0}^{3} \beta_{j i \tau}^{k} \cdot 1\left[c \in R_{j}\right] \cdot 1\left[t \in S_{i}\right] \cdot w_{c, t-\tau}^{k}+\epsilon_{c t}
$$

where $\Delta l_{c t}$ is the change in log non-seasonally-adjusted private nonfarm employment in county $c$ and month $t . \gamma_{s t}$ is an industry-specific time (month of sample) fixed effect, which absorbs all national common factors such as business cycles, oil price shocks, foreign economic shocks, monetary policy changes, and federal fiscal or regulatory policy changes. $\alpha_{c, m(t), d(t)}$ is a county-specific calendarmonth*decade fixed effect. The inclusion of this fixed effect has the effect of seasonally adjusting

\footnotetext{
${ }^{13}$ The implied weekly weights for a given variable are the coefficient for that week divided by the sum of the coefficients over the four weeks.

${ }^{14}$ Wilson (2017) uses a similar empirical model to explore nonlinear temperature effects, the extent to which local economies adapt to their long-run climates, and the extent to which the aggregate economy has become more or less sensitive to weather over time. It also estimates industry-specific models, the results of which show that the most weather-sensitive industries are Mining and Logging, Construction, Retail Trade, Leisure and Hospitality, and Manufacturing. Other recent studies also have used county panel data to investigate the local economic impacts of weather. See Deschênes and Greenstone (2007) for results on annual agricultural profits, Deryugina and Hsiang (2014) on annual income, and Graff-Zivin and Neidell (2014) and Connolly (2008) on time use allocated to work vs. leisure.
} 
employment growth, where seasonal patterns are specific to each county and are allowed to vary by decade. $^{15}$

The $\beta_{j i \tau}^{k}$ are the key parameters to be estimated. They capture the effect of each weather variable (indexed by $k$ ), by season (i) and by region $(j)$, on employment growth in the current month and up to three months ahead. $1\left[c \in R_{j}\right]$ is an indicator equal to 1 if county $c$ is in region $R_{j} ; 1\left[t \in S_{i}\right]$ is an indicator variable equal to 1 if month $t$ is in season $S_{i}$; and $w_{t-\tau}^{k}$ is one of $\mathrm{K}$ weather variables for the month $t-\tau$. Seasons are defined as follows: Winter = December, January, and February; Spring = March, April, and May; Summer = June, July, and August; and Fall = September, October, and November. The regions are the nine Census Bureau regions. I include five monthly weather variables: average daily precipitation (millimeters), average snowfall (centimeters), average daily high temperature (degrees Fahrenheit), the number of days in which the low temperature is below $30^{\circ} \mathrm{F}\left(-1.1^{\circ} \mathrm{C}\right)$, and the number of days in which the high temperature is above $90^{\circ} \mathrm{F}\left(32.2^{\circ} \mathrm{C}\right)$.

The model is estimated using weighted OLS, where the weights are log county employment. The weighting is done to mitigate the influence of sparsely populated counties. Measurement error in the weather data is likely to be inversely proportional to population given that less populous counties generally have fewer or no weather stations and thus the weather data for these counties relies more heavily on spatial interpolation. In addition, to mitigate the influence of measurement error and outliers in the dependent variable, I winsorize employment growth at the $1^{\text {st }}$ and $99^{\text {th }}$ percentiles (i.e., values below the $1^{\text {st }}$ and above the $99^{\text {th }}$ percentiles are replaced with the $1^{\text {st }}$ and $99^{\text {th }}$ percentile values, respectively).

Without any constraints imposed, the above model contains $720 \hat{\beta}_{j i \tau}^{k}$ parameters $^{16}$ - too many to be estimated with reasonable precision. To reduce this number while retaining the economically important sources of heterogeneity in weather effects, I impose some realistic constraints. First, note that there is already in equation (1) a constraint imposed by the number of lags included in the model. The model assumes that lags beyond 3 months have no effect, which is supported by a Wald test involving comparing the baseline model to a model with 4 lags. However, there are no constraints imposed on the lag structure within that lag length. This allows for the possibility of permanent (or at least persistent) weather effects and transitory (mean-reverting) weather effects. Second, I consider constraints on season heterogeneity. In particular, temperature seems likely to have different effects in the spring and winter, when warmer days may well boost economic activity, than in the summer,

\footnotetext{
15 The BLS does not provide seasonally-adjusted QCEW data at the county level.

${ }^{16} 5$ weather variables $X 9$ regions $X 4$ seasons $X 4$ lags.
} 
when warmer temperatures may have less positive, or even adverse, effects. Yet, a reasonable (and testable) constraint on the model might be to assume the other weather variables - snow, number of days below $30^{\circ} \mathrm{F}$, number of days above $90^{\circ} \mathrm{F}$, and precipitation - have approximately the same marginal effects on employment growth throughout the year. ${ }^{17}$ Hence, I impose this joint constraint and test the constraint via a Wald test.

A priori, regional heterogeneity in weather effects seems important and it is largely absent from previous studies. ${ }^{18}$ Weather is inherently a local phenomenon and its primary economic impacts are felt locally; national average effects may be of limited value. On the other hand, allowing for full regional heterogeneity could lead to overfitting. Hence, I estimate two versions of the DPD model: one version with full regional heterogeneity $(\mathrm{RH})$, as in equation (1), and one version without regional heterogeneity (no-RH) - that is, with each $\hat{\beta}_{j i \tau}^{k}$ assumed to be equal across regions $\left(\hat{\beta}_{j i \tau}^{k}=\hat{\beta}_{i \tau}^{k}\right)$. The $\mathrm{RH}$ model yields $288 \hat{\beta}_{j i \tau}^{k}$ parameters while the no-RH model yields $32 \hat{\beta}_{i \tau}^{k}$ parameters.

The RH and no-RH models capture the effects of local weather on local employment growth. It is possible that local employment growth is also affected by weather in other places through spatial spillovers of local economic shocks. There are a variety of potential channels for such spillovers, and spillovers can be positive and negative. For instance, a shock that boosts income in one county can positively affect economic activity in nearby counties, especially in non-tradable goods and services, due to cross-border shopping and commuting. On the other hand, such a shock could raise local and nearby-county wages and thus negatively affect labor demand in nearby counties. There's also the possibility that local shocks affect economic activity in faraway places. For example, vacation destinations across the country compete with one another. A negative weather shock in one destination can increase tourism in other destinations. In addition, a shock affecting the local tradable-

\footnotetext{
${ }^{17}$ Note that this constraint on marginal effects $\left(\beta^{k}\right)$ does not preclude these weather variables from having different predicted total effects $\left(\beta^{k} w_{c s t}^{k}\right)$ across seasons. For instance, though the effects of one centimeter of snowfall is assumed to be the same in all seasons, snowfall will typically be zero in summer months for most counties and hence will typically have no predicted effect on employment growth in those county-months while its predicted effect in winter months will typically be non-zero due to positive snowfall.

${ }^{18}$ Neither Boldin and Wright (2015) nor Bloesch and Gourio (2015) explicitly allow for regional heterogeneity in weather effects, however they do measure aggregate weather based on deviations-from-normal-weather at the city (Boldin and Wright) or state (Bloesch and Gourio) levels. Thus, the underlying assumption is not that all places respond the same to an inch of snow or an extra degree of temperature, but that all places respond the same to an inch of snow above their average or an extra degree of temperature above their average. It should also be noted that Boldin and Wright, in some specifications, include the Regional Snowfall Index (RSI) provided by the National Centers for Environmental Information (NCEI)(see Squires et al. 2014), which incorporates some regional heterogeneity in snowfall effects. The RSI rates snowstorms based on their "societal impact," where the latter is based on the severity of the storm, its spatial extent, and its nexus with population centers. However, the index only covers storms in the eastern two-thirds of the United States and only covers the subset of storms NCEI considers "major" (roughly 5 per year).
} 
goods sector can affect final goods prices faced by consumers and intermediate input costs faced by producers in other parts of the country.

If such spillovers exist, national aggregates of the local weather effects derived from the $\mathrm{RH}$ and no-RH models may be biased. Hence, I also consider a version of the no-RH model that incorporates spatial lags of each weather variables (and its three time lags). The spatial lag of a variable for a given county is simply a weighted average of that variable in other counties, where the weights measure the spatial linkage between the focal county and each other county. A common approach is to weight by the inverse of the geographic distance between population centroids (from U.S. Census Bureau data). This is the primary approach I follow for the spatial lag models used in the paper. However, I also obtained results from model where the spatial lags are constructed from an equal-weighted average of counties 1,000 or more miles away from the focal county (again based on distance between centroids).

\section{Estimated Models of Local Weather Effects}

In this section, I briefly present the results from estimating three alternative county DPD models: (1) the model without regional heterogeneity in the marginal effects of weather (no-RH), (2) the model with regional heterogeneity $(\mathrm{RH})$, and (3) the model accounting for potential spatial spillovers of weather in other counties affecting employment growth in the focal county (SL).

Each weather regressor is normalized by its full-sample standard deviation so that the coefficient magnitudes can be compared across the different weather variables. Each coefficient represents the effect on local employment growth of a one standard deviation change in that weather measure.

The coefficients and standard errors from estimating equation (1) for the version of the model without regional heterogeneity are shown in Table 2. Recall that the dependent variable is private nonfarm employment growth. The regression uses a balanced panel of 1,329,900 observations from 3,100 counties. The panel covers 429 months from January 1980 to December 2015. The standard errors are robust to heteroskedasticity and allow for two-way clustering of the residuals. The first cluster group is county. Clustering by county allows for any form of within-county serial correlation. The second cluster group is state*sample-month, which allows for cross-sectional spatial correlation across counties within a state. Allowing for this cross-sectional spatial correlation accounts for both the natural spatial correlation of weather across local areas but also any correlation introduced by the 
fact that neighboring counties may use data from the same weather station(s) in the process of constructing the weather variables for their county.

The first column of the table shows the estimated coefficients and their standard errors on the contemporaneous values of the weather variables. The second, third, and fourth columns show the coefficients and standard errors for the one-, two-, and three-month lagged values, respectively. The implied four-month cumulative effect is provided in the final column. The estimates indicate that higher temperatures have a positive and statistically significant contemporaneous effect on employment growth in all four seasons. The effects are economically significant as well. For instance, in spring months, a one standard deviation $\left(18.1^{\circ} \mathrm{F}\right)$ increase in temperature is associated with 0.11 percentage point higher employment growth in the same month. Note that average monthly employment growth in the sample is 0.08 percentage point (see Table 1), so this spring temperature effect represents more than a doubling relative to baseline employment growth. ${ }^{19}$ The contemporaneous effect of temperature is largest in the spring and smallest in the fall. Precipitation and snowfall have modest negative contemporaneous effects; both are significant at below the $1 \%$ level. The percentage of days in the month in which the high temperature exceeded $90^{\circ} \mathrm{F}$ and the percentage of days in which the low temperature fell below $30^{\circ} \mathrm{F}$, holding constant the average daily high temperature over the month, each have negative point estimates, though the latter is only weakly statistically significant.

The lagged effects tend to be of opposite sign to the contemporaneous effect and largest for the first two lags. Over the course of four months, the implied cumulative effect is close to zero and statistically insignificant for average daily-high temperature, with the exception of a small and weakly significant effect in the winter. Precipitation has a negative contemporaneous effect but positive cumulative effect, while snowfall has a negative cumulative effect. The number of days above $90^{\circ} \mathrm{F}$ has a negative effect on employment growth in the current month and up to 3 months later, leading to a sizable negative cumulative effect. Though it is difficult to know the mechanisms underlying such effects, one possible explanation for this last effect is that very hot days increase business operating costs (e.g., air conditioning) which, if persistent over several months, can significantly dampen employment growth.

Due to the very large number of weather effect parameters (288, not counting implied cumulative effects), estimates of the model with regional heterogeneity are not shown here. The

\footnotetext{
${ }^{19}$ Note that monthly employment growth of 0.08 percentage points (p.p.) is equivalent to roughly 1.0 p.p. growth at an annual rate.
} 
positive and significant contemporaneous temperature effects, especially in the spring, shown in Table 2 are found to be broad-based across regions, though they tend to be largest in the Pacific region. The contemporaneous effect of the number of very hot days, which is negative, also is found to be largest in the Pacific region. The contemporaneous effect of precipitation is fairly broad-based, though the effect is largest in New England and the East North Central and the East South Central regions. Lastly, snowfall's negative effect appears to be most pronounced in the South Atlantic and East South Central, two of the three regions with the lowest average snowfall. Consistent with the findings from the no- $\mathrm{RH}$ model, the cumulative effects of weather are generally close to zero in all regions, with some exceptions. Notable exceptions are that higher temperatures in New England have persistent negative effects on employment growth in both the summer and the winter, and higher temperatures in the Pacific region have persistent positive effects on spring employment growth. Precipitation also has a cumulative negative effect in New England. The number of very cold days has negative cumulative effects in a few regions, especially in New England, the East North Central, and the Mountain region. Lastly, I find that the number of very hot days has negative cumulative effects in several regions and especially in the Pacific region (consistent with the negative contemporaneous effect in that region) and the South Atlantic.

The results from estimating a version of the panel data model without regional heterogeneity but with spatial lags (SL) are shown in Table 3. For each weather variable (contemporaneous and lagged values) included in the no-RH model (Table 2), the SL model includes that variable plus its spatial lag. The spatial lags here are based on inverse-distance weighting of other counties, where distance is measured between the population centroid of the focal county and each other county. Compared with the results in Table 2, the own-county effects are, in general, qualitatively similar but quantitatively smaller and less likely to be statistically significant. For instance, as in Table 2, the average daily high temperature has a large positive, but transitory, immediate effect on employment growth in the spring and the winter. Contrary to the results in Table 2, however, the own-county effects for temperature in the summer and fall from the SL model are near-zero contemporaneously but negative and significant over a four-month period.

The spatial lag effects - that is the effects of weather in nearby counties - are often large, though estimated somewhat imprecisely, and generally are in the same direction as the own-county effects. In particular, contemporaneous own-county employment growth is boosted when nearby counties experience higher spring and summer temperatures, lower precipitation, and lower snowfall. Spatial lags of temperature in the summer and fall have positive cumulative effects while the spatial 
lag of the number of very hot days has a negative cumulative effect. These results potentially suggest that spatial spillovers of weather to nearby places tend to be positive (i.e., in the same direction as own-county effects). However, it is also possible that county level weather contains measurement error and that spatial lags of weather, by averaging weather measurements across nearby counties, provide a less noisy measure of own-county weather (in addition to picking up any spatial spillovers). I am agnostic here as to which interpretation is more accurate. Either case implies that the SL model, when aggregated, could potentially provide a better in-sample and out-of-sample fit for national employment growth. ${ }^{20}$

\section{Estimating National Weather Effects, Historically and in Real-Time}

The county panel models estimated above can potentially be useful in estimating the effects of weather on national economic activity, historically and in real-time. In this section, I show how these estimated county panel models can be used to obtain estimates of the overall weather effect on any given month's employment growth at the county level, which can then be aggregated to the national level. I then use this methodology to estimate national weather effects, and I evaluate the extent to which these weather effects can explain national payroll employment growth as well as employment data surprises and financial market returns on employment release days.

\section{A. Methodology}

The first step in obtaining the estimated overall weather effect for a given county and month is to obtain the fitted values of employment growth from estimating the county DPD model (equation (1)):

$$
\hat{\Delta} l_{c t}\left(\mathbf{w}_{\mathrm{ct}}\right)=\hat{\gamma}_{t}+\hat{\alpha}_{c, m(t), d(t)}+\sum_{k=1}^{K} \sum_{j=1}^{9} \sum_{i=1}^{4} \sum_{\tau=0}^{3} \hat{\beta}_{j i \tau}^{k} \cdot 1\left[c \in R_{j}\right] \cdot 1\left[t \in S_{i}\right] \cdot w_{c, t-\tau}^{k}
$$

where $\mathbf{w}_{\mathbf{c t}}$ is the vector of weather variables, $w_{c, t-\tau}^{k}$. Thus, $\hat{\Delta} l_{c t}\left(\mathbf{w}_{\mathbf{c t}}\right)$ is predicted local employment growth as a function of national factors (captured by the time fixed effect), seasonal factors (captured by the county*calendar-month*decade fixed effect), and actual weather in the current and past three months.

\footnotetext{
${ }^{20}$ I also have estimated a version of the SL model replacing the inverse-distance spatial lags with the 1,000-miles-plus distance spatial lags, as mentioned in the previous section. In general, the estimates suggest unfavorable weather in faraway counties tends to boost employment growth at home. This model, however, yields aggregate weather effect estimates with a very weak fit for national payroll employment growth.
} 
The second step is to obtain counterfactual estimates of employment growth had weather that month been equal to its historical average for that county, calendar month, and decade: $\hat{\Delta} l_{c t}\left(\overline{\mathbf{w}}_{\mathbf{c}, \mathbf{m}(\mathbf{t}), \mathbf{d}(\mathbf{t})}\right)$, where $\overline{\mathbf{w}}_{\mathbf{c}, \mathbf{m}(\mathbf{t}), \mathbf{d}(\mathbf{t})}$ is the vector of weather variables where each is set equal to their county*calendar-month*decade mean. The difference between predicted employment growth given actual weather and predicted employment growth given average weather, $\Omega_{c t}=\hat{\Delta} l_{c t}\left(\mathbf{w}_{\mathbf{c t}}\right)-\hat{\Delta} l_{c t}\left(\overline{\mathbf{w}}_{\mathbf{c}, \mathbf{m}(\mathbf{t}), \mathbf{d}(\mathbf{t})}\right)$, is an estimate of the overall weather effect for that county and month. One can then sum these local growth effects, using employment weights, to get an estimate of the national weather effect on employment growth for a given month:

$$
\Omega_{t}=\sum_{c}\left(\frac{L_{c t}}{L_{t}}\right) \Omega_{c t},
$$

where $L_{t} \equiv \sum_{c} L_{c t}$.

Because weather data is collected and made public by NOAA in nearly real-time - it is released with a one-day lag - such estimates of national weather effects can be produced both historically and concurrently with, or even a few days in advance of, the BLS' monthly release of national payroll employment growth, which leads the release of QCEW data by six to eight months. In other words, national aggregates of the fitted county DPD model can provide both "backcasts" (historical estimates) and "nowcasts" (real-time estimates) of weather's effect on national employment growth.

\section{B. In-Sample and Out-of-Sample Fit for National Employment Growth}

Policymakers and others often want to know the effect of weather in a given (typically the latest) month on national employment growth and other macroeconomic outcomes. A common approach is to estimate the historical relationship between weather, measured using national (crosssectional) averages, and the national outcome in question using a time series regression, and then obtain weather effect estimates using a methodology similar to that described above. The rich heterogeneity of weather effects in the county DPD model and the precision of its estimates based on large degrees of freedom offer the potential of better explaining national weather effects.

However, there are two potential disadvantages. First, the county model is estimated using the QCEW data on employment. While the QCEW, being a census from administrative records rather than a survey, is likely a more accurate measure of employment than that from the CES payroll survey, the QCEW data are released with a several-month lag while the payroll survey's employment data is 
available in nearly real-time and hence is followed closely by policymakers and the public. Thus, estimates of the national weather effect based on the county DPD model using QCEW data may not be able to explain national CES employment growth as well as a simple national time series model based on CES data. ${ }^{21}$ Second, though one can attempt to capture spatial spillover effects via spatial lags in the county model, the true nature of spatial spillovers is unobserved. If these spillovers are quantitatively important and not fully captured by any spatial lags included in the county model, then the national effects obtained by aggregating across counties will be mismeasured.

To assess whether the advantages outweigh the disadvantages or vice-versa, I evaluate the insample and out-of-sample explanatory power of the national weather effect estimates derived from the county DPD model compared to estimates derived from a national time series model. The latter estimates are based on the same methodology as in the previous subsection - predicted values using actual weather minus predicted values using average weather - but using the following time series regression to obtain the fitted model:

$$
\Delta l_{t}^{C E S}=\sum_{k=1}^{K} \sum_{i=1}^{4} \sum_{\tau=0}^{3} \beta_{i \tau}^{k} \cdot 1\left[t \in S_{i}\right] \cdot \tilde{w}_{t-\tau}^{k}+\alpha_{S(t)}+\epsilon_{t}
$$

where $\Delta l_{t}^{C E S}$ is seasonally-adjusted payroll employment growth from the official BLS Current Employment Situation (CES) series. This is the payroll employment series commonly reported on in the media each month and that is closely tracked by policymakers and the public. The regressor, $\tilde{w}_{t-\tau}^{k}$, for each weather variable $k$, is the national employment-weighted average of the county-level deviation of that variable from its county*calendar-month*decade average. That is, the regressor captures the extent to which weather across the county deviated from local seasonal norms in that month. $\alpha_{S(t)}$ is a season fixed effect (see text after equation (1) for season definitions), which is included to account for potential residual seasonality not captured by the BLS seasonal adjustment of employment.

This national model is estimated using the same sample period as that used for the county DPD model, January 1980 to December 2015. The estimated coefficients and standard errors are shown in Table 4. The effects of weather implied by the national time series regression are

\footnotetext{
${ }^{21}$ Note that the historical CES employment levels are annually benchmarked to the QCEW employment levels. However, the two series vary independently within the year. Also, the published CES data are seasonally adjusted using the Census X13 algorithm which is a different technique for seasonal adjustment than that which underlies our countyDPD/QCEW estimates of weather effects. The latter relies on seasonal adjustment within the county DPD regressions via county*calendar-month*decade fixed effects.
} 
considerably different, and estimated much more imprecisely, than those obtained from the analogous county DPD model without regional heterogeneity (Table 2). In fact, none of the contemporaneous weather variables are statistically significant, though several have economically significant coefficients. For instance, the number of days in the month with minimum temperature below $30^{\circ} \mathrm{F}$ is estimated to have a large negative effect on employment growth, both contemporaneously and cumulatively, though only the cumulative effect is statistically significant.

In addition to the estimated national weather effects based on the fitted national model shown in Table 4, I calculate national weather effects based on three alternative versions of the county DPD model. The first is the county DPD model with regional heterogeneity $(\mathrm{RH})$; the second is the county model without regional heterogeneity (no-RH), as in Table 2; and the third is same model but including inverse-distance-based spatial lag terms, as in Table 3 (SL).

To assess the power of each model's estimated national weather effects for explaining/predicting national payroll employment growth, I regress private nonfarm employment growth (from the CES payroll survey) on that model's national weather-effect series. For in-sample, backcasting evaluations, the county and national models are estimated using the sample described above, from January 1980 to December 2015.

The results from regressing payroll employment growth on each model's implied weather effects are shown in Table 5. Specifically, the table reports the estimated slope coefficient from each of these bivariate time series regressions - i.e., the coefficient on the weather effect - and its standard error, as well as the $\mathrm{R}^{2}$. In sample, the national model yields the best fit (highest $\mathrm{R}^{2}$ ). Moreover, the implied weather effect from that model is highly statistically significant. The full-sample $\mathrm{R}^{2}$ is considerably lower for the county models, with the county spatial lag model having the worst fit. Nonetheless, the weather effect estimates from the RH and no-RH versions of the county model are statistically significant. Note that for the national model, this regression is in essence equivalent to the regression in Table 4, since that regression uses the same dependent variable and the same sample period, while the regressor in Table 5 is just the predicted values from the regression in Table 4. Hence, the fact that the national model's implied weather effects give the best in-sample fit is not surprising; after all, that model is fitted to minimize the sum of squared errors (via OLS).

The more relevant question is which model yields the best fit out of sample. In particular, an analyst or policymaker would like to know which model specification would be most useful for estimating weather's effect on employment growth in the current month, even before that month's employment data is released. In other words, which model is best for "nowcasting"? A model with 
good out-of-sample/nowcasting properties could be useful to policymakers and market participants attempting to gauge the employment implications of weather in the current or most recent month, especially given that the NOAA weather data is released with only a one-day lag.

I construct rolling out-of-sample nowcasts of the national weather effects as follows. For the county models, I estimated the county DPD model iteratively over sample periods in which the first sample month is fixed at January 1980 and the end-month is iterated from May 2003 to December 2015. For each rolling sample, I calculate the implied county-level weather effect for the month eight months past the end-month and aggregate to the national level (as described in subsection A above). Using eight-month out-of-sample estimates mimics the best an analyst could do in real-time given that county-level QCEW data are released (at a quarterly frequency) with a lag of six to eight months. This process yields a time series of national weather effect nowcasts from January 2004 to August 2016.

For the national model, I estimate the model iteratively over sample periods in which the first month is fixed at January 1980 and the end-month is iterated from December 2003 to July 2016. For each rolling sample, I calculate the implied national weather effect for the month following the endmonth. Using one-month out-of-sample estimates mimics the best an analyst could do in real-time given that the national CES data are released on the first Friday of the month following the reference month. As with the county-model based estimates, this process yields estimated national weather effects from January 2004 to August 2016.

The second row of Table 5 shows the nowcasting/out-of-sample results, where actual payroll employment growth is regressed on the nowcasts of weather effects for each model. All three of the county models yield a better out-of-sample fit than the national model. The county models without spatial lags perform considerably better than the spatial lag model. The $\mathrm{R}^{2}$ 's for the county models with and without regional heterogeneity are very similar, about 0.04 . The weather effects from each of these two county models are statistically significant at below the $5 \%$ level.

In sum, the county models, despite being estimated using QCEW employment data instead of CES data and being estimated at the local rather than national level, yield national weather effect estimates with better nowcasting explanatory power for national CES employment growth than does a national time series model estimated on national CES employment growth data. It is particularly interesting that the county model with no regional heterogeneity, which is exactly the same specification as the national model aside from fixed effects, yields a better out-of-sample fit than the national model. This suggests the advantage afforded by the large degrees of freedom in the county 
DPD regression outweigh the disadvantage of having to rely on a different employment data source at the local level.

\section{Impact of National Weather Effects on Other National Labor Market Outcomes}

Above I found that nowcasts of the national weather effect implied by the estimated county DPD model can help predict national payroll employment growth. Here I consider whether these weather effect nowcasts also help predict other national labor market outcomes. As I did for payroll employment growth in Table 5, for each of several national labor market variables I regress the variable on the national weather effect nowcast from the county DPD model or the national model. For this exercise, I use the county DPD model with regional heterogeneity ("RH"); the results are very similar using the model without regional heterogeneity ("no RH").

The results are shown in Table 6. The results from Table 5 for national CES employment growth are repeated in the first row for comparison. The right-most column shows the p-value on the Giacomini-White $(\mathrm{GW})$ test that the mean squared errors of the two forecasts of employment growth are the same. I find that the county DPD model's weather effects have a statistically significant impact on national CES employment growth, national QCEW employment growth, the vacancy rate, and the hires rate. ${ }^{22}$ Weather effects from the national model are statistically insignificant in all of these cases. Furthermore, the $\mathrm{R}^{2}$ is higher using the county DPD model's weather effects in every case, though the GW test fails to reject the null that their predictive power is the same.

I also consider the predictive power of the weather effect nowcasts on payroll employment growth broken out by establishment size class (from national CES data). ${ }^{23}$ The results are shown in rows 6-8 of Table 6. Interestingly, the county model's nowcast is most powerful at predicting employment growth at small establishments (less than 50 employees), while the national model is best at predicting employment growth at very large establishments (more than 500 employees). It is possible that small establishment employment growth is particularly sensitive to local weather (and insensitive to non-local weather), and hence the local model is particularly good at capturing those effects. Large establishment employment growth, on the other hand, may be less sensitive to local

\footnotetext{
${ }^{22}$ Like county level QCEW data, national QCEW data is not seasonally adjusted. For these regressions, I seasonally adjust QCEW employment growth by taking the residual from a regression of raw QCEW employment growth on calendar-month dummies.

${ }^{23}$ Unfortunately, the QCEW data only provide employment by size class for the first quarter of each year, so it is not possible to estimate a county DPD model for local employment growth by size class.
} 
weather and more sensitive to non-local/nationwide weather, and hence the national model is somewhat better at predicting employment growth at large establishments.

Next, as a type of cross-validation exercise, I estimate the relationship between the weather effect nowcasts and the monthly change in the rate of self-reported work absences due to weather from the household survey portion of the employment report. In the household survey (i.e., the Current Population Survey), respondents are asked if they were employed but absent from work during the week containing the $12^{\text {th }}$ of the month. Those that say yes are asked which of the following was the reason for the absence: vacation, illness, bad weather, labor dispute, or "other reasons"? The absence rate is the number of respondents reporting an absence divided by total household-survey employment. The penultimate row of Table 6 shows that the weather effect nowcasts are strongly negatively related to the change in the weather-absences rate. That is, in months in which the nowcasts indicate that recent weather positively (negatively) affected employment growth, the rate of work absences due to bad weather tends to fall (rise). By contrast, the nowcasts from the national model have virtually no correlation with reported work absences due to bad weather.

Lastly, as a falsification test, I evaluate whether the weather effect nowcasts are correlated with the monthly change in the rate of work absences for non-weather reasons. The final row of Table 6 shows that, as expected, the nowcasts have no significant relationship with non-weather related absences.

The results in Table 6 are also informative regarding the extent to which the county model's implied national weather effects capture the true effect of weather on national employment growth. That is, they are informative as to how well the county model is able to overcome the two challenges inherent in using county data to estimate national weather effects on CES payroll employment growth: (1) using QCEW data instead of CES data in the model estimation and (2) estimating at the county level and aggregating instead of estimating at the national level. If the model perfectly captured the true weather effect, one would expect a slope coefficient of one when the dependent variable is private nonfarm employment growth. ${ }^{24}$ When this is measured using the aggregated QCEW data, we obtain a slope coefficient of 1.041, suggesting little if any measurement error is introduced by the countyto-national mapping. When employment growth is measured using the CES data, the slope coefficient falls a bit, to 0.899 . While this is not statistically significantly different from one, the drop in the point estimate below one suggests there is some amount of measurement error introduced by the mismatch

\footnotetext{
${ }^{24}$ Note that even with a slope coefficient of one, we might expect a low $\mathrm{R}^{2}$. The low $\mathrm{R}^{2}$ would simply reflect that a small fraction of the variation in employment growth is due to weather.
} 
between the QCEW and CES. That mismatch could be due to differences between the two data sources in coverage, employment definition, and seasonal adjustment methods.

\section{Predictive Power for Employment Report Surprises and Asset Prices}

\section{A. Predictive Power for Payroll Employment Report Surprises}

While the $\mathrm{R}^{2}$ 's for payroll employment growth in Table 5 from the county-based models are greater than that for the national model, they are still fairly low, at about 0.04 . Even if one measured the employment growth weather effect perfectly, this $\mathrm{R}^{2}$ likely would be quite low, indicating that a relatively small fraction of the variation in employment growth is due to weather as opposed to other factors. It is quite possible, however, that these other factors - e.g., strikes, financial conditions, and overall economic conditions - are largely observed and known to policymakers, market participants, and other analysts interested in tracking real-time employment growth (i.e., "nowcasting"). The national weather effect, on the other hand, may not be well observed given that it requires both a rich understanding of weather's local effects and real-time local weather data. In that case, one would expect the weather effect to predict the unanticipated, or "surprise," component of national employment data releases. Moreover, to the extent that the weather effect predicts employment surprises, one might also expect an effect on financial market asset prices on employment report release days given the strong sensitivity of asset prices to employment surprises. ${ }^{25}$

I investigate these conjectures in Table 7 and Figure 1. I measure monthly surprises to total nonfarm employment growth by the difference between actual, real-time (as first reported) employment growth and the median forecast of employment growth from a survey of economists and market participants conducted in the few days prior to the employment report. The survey and realtime data, from January 1990 to present, come from Money Market Services (MMS)/Action Economics and have been used previously in event studies of the financial market responses to macroeconomic data releases (see, e.g., Gurkaynak, Sachs, and Swanson 2005).

I regress employment growth surprises on estimated national weather effects. I consider this relationship both for the weather effect backcasts derived from the full-sample county DPD

\footnotetext{
${ }^{25}$ Note that payroll surprises should only affect asset prices to the extent that market participants perceive the surprise as reflecting news about cash flow or discount rate fundamentals. Payroll surprises perceived to have been due to transitory idiosyncratic factors, such as weather, should not affect asset prices. Hence, the hypothesis here is that the effect of current and lagged weather on employment is not fully observed/measured by market participants, in which case payroll surprises driven by weather can be misconstrued by the market as representing fundamentals, rather than weather, and hence affect asset prices. In addition, because the market does not recognize in such cases that the payroll surprise was actually driven by weather effects, there is no reason to expect the equity price response to be any different in weather-sensitive sectors than in non-weather-sensitive sectors.
} 
estimation and the weather effect nowcasts derived from the rolling out-of-sample series of estimations (described in Section IV.B). The regression results are shown in the top row of each panel in Table 7. Panel A shows the results for the backcasts while Panel B shows the results for the nowcasts. In addition, these relationships are shown graphically via bin-scatter plots in the top two panels of Figure 1. ${ }^{26}$ Table 7 provides results for weather effects estimates based on both the county model without regional heterogeneity (Columns 1-2) and the model with regional heterogeneity (Columns 3-4). The sample period for the employment growth surprise regressions in Panel A covers December 1989 to August 2016. (The MMS survey data necessary for constructing the surprises begins with December 1989.) The sample period for the regression in Panel B is January 2004 (the first month of the nowcasts) to August 2016.

The results in Panel A indicate that the backcasts have a highly significant effect on the surprise component of employment growth, suggesting that, historically, market participants did not, or were unable to, fully account for the local effects of weather when forming their expectations of the latest month's employment growth. The $\mathrm{R}^{2}$ is around 0.10 for both the no- $\mathrm{RH}$ and $\mathrm{RH}$ model based estimates, suggesting that weather is a significant, but not a dominant, factor in explaining unanticipated fluctuations in reported employment growth.

Panel B of Table 7 and the right-hand side of Figure 1 shows the analogous results based on the nowcasts. Recall that the nowcast of the weather effect for a given month uses only data that would be available to an analyst prior to that month's employment report. These nowcasts are able to explain around 15 percent of the variation in employment growth surprises. The slope coefficient in the regressions is around 0.4 and is highly statistically significant.

\section{B. Predictive Power for Stock Market Returns and Treasury Bond Yield Changes on Report Days}

Given this strong correlation between the estimated weather effects and employment growth surprises, and the well-known sensitivity of asset prices to macroeconomic data surprises, I evaluate the impact of the estimated weather employment effect on the stock market return and Treasury bond yield change on the day of the corresponding employment report release. ${ }^{27}$ The asset price changes

\footnotetext{
${ }^{26}$ Each panel in Figure 1 contains a bin-scatter plot showing the relationship between the indicated outcome variable $(y$-axis) and the national employment weather effect estimate ( $x$-axis). Each point shows the mean $x$ and $y$ values within a bin. Bins are defined according to 30 quantiles of the $x$ variable. The shown fit line is based on a linear regression of the outcome variable on the national employment weather effect, using the raw data (not the binned data). Thus, the fit lines match the regression results shown in Table 7.

27 The employment reports are generally the dominant macroeconomic news on their release days. Possible exceptions are the eight observations $(3 / 7 / 80,12 / 5 / 80,9 / 7 / 90,12 / 7 / 90,2 / 1 / 91,3 / 8 / 91,12 / 6 / 91$, and 9/4/92) in which there was an unscheduled FOMC policy announcement made on the same day as the employment report. The full-sample results are
} 
are calculated from the close of the prior market day to the close of the market day on which the employment report occurs. ${ }^{28}$ For comparison, Column 5 of Table 7 shows the slope coefficient and standard error from a regression of the indicated dependent variable for that row on the payroll employment growth surprise. Column 5 in Panel A shows that for this December 1989 to August 2016 sample period, employment growth surprises have no clear average effect on stock market returns (on the days of the employment report release) but have a strong positive effect on the Treasury bond yield change on those days. These results are consistent with prior empirical and theoretical research on the effect of macroeconomic data news on stock and bond returns. ${ }^{29}$ Positive data news have ambiguous effects on stock returns but unambiguously positive effects on Treasury yields because positive news not only can signal higher future earnings, boosting stock prices today, but can also raise the discount rate, which both lowers current stock prices and raises current Treasury yields.

The full-sample results of regressing the stock market returns and yield changes on the weather effect backcasts are shown in the remainder of Table 7, Panel A, and the lower three panels on the left side of Figure 1. The backcasts based on the county no-RH model have a positive and significant association with the S\&P 500 index daily return. The impact on the Dow-Jones index return is significant at the $10 \%$ level for both county models. The weather effects have a stronger association with the Treasury bond yield changes, particularly for the medium-length maturities of two, five, and ten years. This mirrors the pattern of the effect of employment surprises themselves on Treasury yields (column 5).

The analogous nowcast results are shown in Table 7, Panel B and the right side of Figure 1. First, notice that during this sample period (Jan. 2004 - Aug. 2016), employment growth surprises have a strong positive effect on both Treasury yield changes and stock market returns on the days of the employment reports. Consistent with that effect, the weather effect nowcasts also have a positive and significant effect on the stock market returns and the change in Treasury bond yields on the days

\footnotetext{
virtually unchanged if these observations are dropped. The rolling out-of-sample results are unaffected because these dates are all prior to the rolling out-of-sample evaluation period. It is also possible that employment report releases coincide with other important macroeconomic or financial news. One approach to dealing with this issue would be to use intraday changes in asset prices for narrow windows of time around the employment report. However, intraday Treasury data is only available from June 1991 onward, so this would result in the loss of more than one decade's worth of observations for the full sample regressions.

${ }^{28}$ The regressions for stock market returns exclude seven observations (four of which are in the rolling out-of-sample window) in which the employment report occurs on a "Good Friday" holiday because the NYSE is closed on those days.

${ }^{29}$ For instance, McQueen and Roley (1993), Boyd et al. (2005), and Andersen et al. (2007) all find that the response of stock prices to macroeconomic news is small on average and varies along the business cycle, with positive responses to "good" macroeconomic news during contractions and negative responses during expansions.
} 
of employment report releases. ${ }^{30}$ As with the full-sample, the Treasury yield effects are strongest for maturies between two and thirty years. For stock returns, the nowcasts and the employment surprises themselves explain only a small share of the variation (2-4 percent), consistent with the somewhat ambiguous relationship in the literature between positive macroeconomic data news and stock returns mentioned above. For release-day changes in Treasury yields, though, employment surprises explain close to a third of the variation when looking at medium-term maturities. The weather effect nowcasts explain as much as $6.1 \%$ of the variation in yield changes, depending on the maturity.

Another way to assess the predictive power of the weather effect nowcasts for data surprises and asset price changes on employment report days is to compare the means of these variables over all days to their means over days when the nowcast is positive and over days when the nowcast is negative. These means are shown in Table $8 .^{31}$ The first row shows the mean payroll employment growth surprise over all employment report release days between January 2004 and August 2016 (Column 1), over those release days in which the nowcast is positive (Column 2), and over those release days in which the nowcast is negative (Column 3). Note that over this period, which of course contained the Great Recession and its slow recovery, employment reports tended to surprise on the downside over this period. Specifically, the average release reported a monthly employment growth rate that was about 0.8 percentage point (p.p.) lower than the median expectation. Yet, on release days in which the weather effect nowcast is positive, the average surprise was a positive 0.9 p.p., so 1.7 p.p. above the entire sample average. On release days in which the nowcast is negative, the average surprise was -2.3 p.p., or 1.5 p.p. below the entire sample average.

The second and third rows of Table 8 show means for stock market returns over various samples. For all trading days from January 1, 2004 through August 31, 2016, the mean daily stock market return is just $0.02 \%$, according to either index. The mean stock return over just employment report release days is also $0.02 \%$. Yet, on release days in which the nowcast is positive, the mean stock return is an order of magnitude larger, at $0.21 \%$. When the nowcast is negative, the mean return is of a similar magnitude but negative. A similar story arises looking at Treasury bond yield changes. Treasury yield changes in general tend to be close to zero on average, but across days in which the nowcast is positive the mean yield change is over 2 basis points for maturities above one year. When

\footnotetext{
${ }^{30}$ The effect on the 30-year Treasury yield is positive but insignificant. The statistical insignificance may reflect the fact that there are fewer observations for these regressions because new issuances of 30-year Treasury bonds were suspended from late 2001 until February 2006.

${ }^{31}$ The nowcasts used to generate Table 8 are based on the county model with regional heterogeneity.
} 
the nowcast is negative, the mean yield change is around -2 basis points for the 2-year, 5-year, and 10-year bonds.

\section{Illustration Based on a Simple Weather-Based Trading Strategy}

To illustrate the economic significance of the predictive power of the nowcasts for asset prices, I evaluate the performance of a simple trading strategy based on the nowcasts. For simplicity and to compare across asset types, I implement the strategy separately for each asset type: the Dow-Jones Industrial index, the S\&P 500 index, and 2-, 5-, 10- and 30-year Treasury bonds. The trading rule is straightforward: when the weather effect nowcast is positive, take a long position in equities or a short position in bonds; when the nowcast is negative, take a short position in equities or a long position in bonds. In other words, if the nowcast indicates employment growth last month was boosted by favorable weather, the strategy calls for buying stocks and selling bonds; if the nowcast indicates employment growth last month was constrained by unfavorable weather, the strategy calls for the opposite. Trades are assumed to be made at the close of the day before the employment report. The trade is unwound, and the balance put into cash, at the end of the day of the report. The balance remains in cash until the day before the next employment report, which implies that the cumulative returns on the strategy can be interpreted as returns in excess of the return on whatever assets the balance is held in on non-report days.

I assume an initial trading balance of 100 in December 2003 and follow the trading rule from January 2004 to August 2016. The weather effect nowcasts are the rolling out-of-sample estimates based on the county model with regional heterogeneity $(\mathrm{RH})$. The panels of Figure 2 show the evolution of the balance from following this trading strategy for each asset type. The panels also provide the cumulative annualized return, the annualized Sharpe ratio, and the success rate over the period, where the success rate is defined as the percentage of trades yielding a positive daily return. ${ }^{32,33}$ The success rates range from $56 \%$ (for the S\&P 500) to $64 \%$ (for the 2 -year Treasury bond)

\footnotetext{
32 The return on a long position in Treasury bonds of maturity $M$ on day $d$ is calculated as: $-M\left(r_{d}-r_{d-1}\right)$, where $r$ is the yield on the bond at the close of day. The return on the short position is simply $M\left(r_{d}-r_{d-1}\right)$. This expression comes from the relation between the price $\left(p_{d}\right)$ of a zero-coupon bond to its face value $(F)$, time to maturity $(M)$, and yield to maturity $\left(r_{d}\right): p_{d}=F\left(1+r_{d}\right)^{-M}$. The rate of return is then approximately:

$$
\log \frac{p_{d}}{p_{d-1}}=\log \left[\frac{\left(1+r_{d}\right)}{\left(1+r_{d-1}\right)}\right]^{-M} \approx-M\left(r_{d}-r_{d-1}\right) .
$$

${ }^{33}$ Because there are 12 employment reports a year, the annualized Sharpe ratio is calculated as the $\sqrt{12}$ times the mean return per report day divided by its standard deviation. The same formula, but with $\sqrt{8}$, is used in Lucca and Moensch (2015) for computing the annualized Sharpe ratio for returns on pre-FOMC announcement days, which occur 8 times a year.
} 
across the asset types. For the stock market indices, the strategy would have earned a roughly $2.1 \%$ cumulative annualized return with a Sharpe ratio of about 0.6. For Treasury bonds, the cumulative annualized return increases with the maturity of the bond, ranging from $0.5 \%$ for 2 -year bonds to $4.5 \%$ for 30 -year bonds. ${ }^{34}$ However, the standard deviation of the returns across the employment report days also increases with the maturity, so the Sharpe ratio is highest, at about 1.0, for the 2- and 5 -year bonds.

\section{Conclusion}

Weather has important short-run effects on economic activity, particularly employment growth, at the local level. This paper asks whether estimates of local weather effects, when aggregated to the national level, can be useful in explaining and predicting movements in aggregate payroll employment as well as asset price responses to payroll employment releases. Using a county-level dynamic panel data (DPD) model and monthly data from January 1980 to December 2015, I estimated the effects of temperature (by season), precipitation, snowfall, the frequency of very hot days, the frequency of very cold days, and storm property damages on private nonfarm employment growth. I then demonstrated how this county DPD model can be used to obtain local weather effects estimates that can be aggregated to the national level. Following this approach in a rolling out-of-sample nowcasting exercise, I found that the monthly national weather effect nowcasts have better explanatory power for the BLS's national payroll employment series than do nowcasts based on a national time series model fitted on that same employment growth data. In addition, the county DPD model's weather effect nowcasts were found to be useful in predicting other national labor market outcomes such as the vacancy rate, hires rate, and quits rate.

Lastly, I showed that these estimated weather effect nowcasts are predictive of the unanticipated, or surprise, component of real-time employment releases, explaining about $15 \%$ of their time-series variation. These nowcasts, in turn, were found also to have predictive power for stock market returns and Treasury yield changes on employment report release days. A simple trading strategy based on the weather effect nowcasts was shown to yield a Sharpe ratio for equities of about 0.6 and for Treasuries bonds of as high as 1.0.

These results are striking in that they suggest that financial markets do not, or are unable to, fully account for the effects of recent months' weather on current month's economic activity. This is

\footnotetext{
${ }^{34}$ Note, however, that the performance of the strategy applied to 30 -year bonds is not completely comparable to that for the other asset types because the sample periods differ; 30-year Treasury bonds were not issued between February 2002 and January 2006.
} 
likely due to some combination of the difficulty and complexities involved with processing the NOAA weather station data, processing the BLS QCEW county-level employment data, deriving a sufficiently rich empirical specification of weather's local employment effects, and properly estimating this specification. In particular, one can imagine market participants having fairly good information about average weather (temperature, snowfall, precipitation, etc.) across the country in a given month. However, understanding the geographic distribution of these weather data and how they correlate with the geographic distribution of employment may be more elusive. In addition, knowing how weather in prior months should affect current employment growth is difficult and arguably requires a precisely estimated empirical model. The vast geographical granularity and high frequency of the data employed in this paper allow for such precise estimation. 


\section{References}

Andersen, Torben G., Tim Bollerslev, Francis X. Diebold and Clara Vega. 2007. "Real-time price discovery in global stock, bond and foreign exchange markets." Journal of International Economics 73, pp. 251-77.

Bloesch, Justin and Francois Gourio. 2015. "The Effect of Winter Weather on U.S. Economic Activity." Federal Reserve Bank of Chicago Economic Perspectives.

Boldin, Michael, and Jonathan H. Wright. Fall 2015. "Weather adjusting economic data." Brookings Papers on Economic Activity.

Boyd, John H., Jian Hu and Ravi Jagannathan. 2005. “The Stock Market's Reaction to Unemployment News: Why Bad News Is Usually Good for Stocks," Journal of Finance, 60 (2), pp. 649-72.

Burgess, Matt. "How frequently do private businesses pay workers?” Beyond The Numbers, Bureau of Labor Statistics, May 2014, Vol. 3 (11). Url: http://www.bls.gov/opub/btn/volume-3/howfrequently-do-private-businesses-pay-workers.htm

Busse, Meghan R., Devin G. Pope, Jaren C. Pope, and Jorge Silva-Risso. 2015. “The Psychological Effect of Weather on Car Purchases." Quarterly Journal of Economics, pp. 371-414.

Connolly, Marie. 2008. "Here Comes the Rain Again: Weather and the Intertemporal Substitution of Leisure.” Journal of Labor Economics 26(1): 73-100.

Deryugina, Tatyana, and Solomon M. Hsiang (2014). "Does the environment still matter? Daily temperature and income in the United States," National Bureau of Economic Research Working Paper \#20750.

Deschênes, Olivier, and Michael Greenstone. 2007. "The Economic Impacts of Climate Change: Evidence from Agricultural Output and Random Fluctuations in Weather," American Economic Review, 97(1): 354-385.

Gilchrist, Duncan S., and Emily G. Sands. 2016. "Something to Talk About: Social Spillovers in Movie Consumption,” Journal of Political Economy 124(5): 1339-1382.

Goetzmann, William N., Dasol Kim, Alok Kumar, Qin Wang. "Weather-Induced Mood, Institutional Investors, and Stock Returns.” Review of Financial Studies 28(1), pp. 73-111.

Graff Zivin, Joshua J., and Matthew Neidell. 2014. "Temperature and the allocation of time: Implications for climate change." Journal of Labor Economics 32(1): 1-26.

Gurkaynak, Refet S., Brian Sack, and Eric Swanson. "The Sensitivity of Long-Term Interest Rates to Economic News: Evidence and Implications for Macroeconomic Models." American Economic Review 95(1): 425-36.

Hirshleifer, David, and Tyler Shumway. 2003 “Good Day Sunshine: Stock Returns and the Weather." Journal of Finance 58(3): 1009-32.

Lazo, Jeffrey K., Megan Lawson, Peter H. Larsen, and Donald M. Waldman. (2011). “U.S. Economic Sensitivity to Weather Variability," Bulletin of the American Meteorological Society, June 2011, pp. 709-720.

Lucca, David O., and Emanuel Moensch. (2015). “The Pre-FOMC Announcement Drift,” Journal of Finance, 70(1), pp. 329-71. 
McQueen, Grant, and V. Vance Roley. 1993. "Stock Prices, News, and Business Conditions." Review of Financial Studies, 6(3), pp. 683-707.

Saunders, Edward M., Jr. 1993. "Stock Prices and Wall Street Weather.” American Economic Review, 83(5), pp. 1337-45.

Squires, Michael F., Jay H. Lawrimore, Richard R. Heim, David A. Robinson, Mathieu R. Gerbush, Thomas W. Estilow, and Leejah Ross. (2014). "The Regional Snowfall Index," Bulletin of the American Meteorological Society, 95, 1835-1848.

Starr-McCluer, Martha. 2000. "The Effects of Weather on Retail Sales.” Mimeo, Federal Reserve Board of Governors. 
Table 1. Effects of Weather by Week on Monthly Employment Growth

\begin{tabular}{|c|c|c|c|c|c|c|}
\hline & $\begin{array}{c}(1) \\
\text { Daily-High Temp }\end{array}$ & $\begin{array}{c}(2) \\
\text { Precipitation }\end{array}$ & $\begin{array}{c}(3) \\
\text { Snowfall }\end{array}$ & $\begin{array}{c}(4) \\
\% \text { days }>90 \mathrm{~F}\end{array}$ & $\begin{array}{c}(5) \\
\% \text { days }<30 \mathrm{~F}\end{array}$ & $\begin{array}{c}(6) \\
\text { Average Implied Weight }\end{array}$ \\
\hline Week 1 & $\begin{array}{c}0.004^{* * *} \\
(0.001)\end{array}$ & $\begin{array}{c}-0.004^{* * *} \\
(0.001)\end{array}$ & $\begin{array}{c}-0.037^{* * *} \\
(0.006)\end{array}$ & $\begin{array}{c}-0.054^{* *} \\
(0.025)\end{array}$ & $\begin{array}{l}-0.027 \\
(0.021)\end{array}$ & 0.297 \\
\hline Week 2 & $\begin{array}{c}0.007^{* * * *} \\
(0.001)\end{array}$ & $\begin{array}{c}-0.004^{* * *} \\
(0.001)\end{array}$ & $\begin{array}{c}-0.040^{* * *} \\
(0.006)\end{array}$ & $\begin{array}{c}-0.102^{* * *} \\
(0.025)\end{array}$ & $\begin{array}{l}-0.007 \\
(0.022)\end{array}$ & 0.341 \\
\hline Week 3 & $\begin{array}{c}0.002^{* * *} \\
(0.001)\end{array}$ & $\begin{array}{c}-0.002^{* *} \\
(0.001)\end{array}$ & $\begin{array}{c}-0.015^{* *} \\
(0.006)\end{array}$ & $\begin{array}{l}-0.016 \\
(0.026)\end{array}$ & $\begin{array}{l}-0.020 \\
(0.021)\end{array}$ & 0.152 \\
\hline Week 4 & $\begin{array}{c}0.002^{* *} \\
(0.001)\end{array}$ & $\begin{array}{c}-0.005^{* * *} \\
(0.001)\end{array}$ & $\begin{array}{c}-0.002 \\
(0.006)\end{array}$ & $\begin{array}{c}-0.049^{*} \\
(0.027)\end{array}$ & $\begin{array}{c}-0.032 \\
(0.023)\end{array}$ & 0.211 \\
\hline
\end{tabular}

$* * * \mathrm{p}<0.01,{ }^{* *} \mathrm{p}<0.05,{ }^{*} \mathrm{p}<0.10$

Table 2. Contemporaneous and Lagged Weather Effects on Employment Growth Industry: All Private Industries

\begin{tabular}{|c|c|c|c|c|c|}
\hline & $\begin{array}{c}(1) \\
\text { Contemporaneous }\end{array}$ & $\begin{array}{c}(2) \\
1 \text { st lag }\end{array}$ & $\begin{array}{c}(3) \\
\text { 2nd lag }\end{array}$ & $\begin{array}{c}(4) \\
\text { 3rd lag }\end{array}$ & $\begin{array}{c}\text { (5) } \\
\text { Cumulative effect }\end{array}$ \\
\hline Avg. daily high temp - Spring & $\begin{array}{c}0.109^{* * *} \\
(0.009)\end{array}$ & $\begin{array}{c}-0.068^{* * *} \\
(0.009)\end{array}$ & $\begin{array}{l}-0.046^{* * *} \\
(0.008)\end{array}$ & $\begin{array}{c}0.005 \\
(0.008)\end{array}$ & $\begin{array}{c}0.001 \\
(0.013)\end{array}$ \\
\hline Avg. daily high temp - Summer & $\begin{array}{c}0.081^{* * *} \\
(0.013)\end{array}$ & $\begin{array}{c}-0.049^{* * *} \\
(0.011)\end{array}$ & $\begin{array}{c}-0.022^{* *} \\
(0.010)\end{array}$ & $\begin{array}{l}-0.014 \\
(0.009)\end{array}$ & $\begin{array}{l}-0.004 \\
(0.017)\end{array}$ \\
\hline Avg. daily high temp - Fall & $\begin{array}{c}0.032^{* * *} \\
(0.010)\end{array}$ & $\begin{array}{l}-0.012 \\
(0.011)\end{array}$ & $\begin{array}{c}-0.028^{* *} \\
(0.012)\end{array}$ & $\begin{array}{c}0.018 \\
(0.013)\end{array}$ & $\begin{array}{c}0.010 \\
(0.019)\end{array}$ \\
\hline Avg. daily high temp - Winter & $\begin{array}{c}0.085^{* * *} \\
(0.010)\end{array}$ & $\begin{array}{c}-0.021^{* *} \\
(0.011)\end{array}$ & $\begin{array}{c}-0.016 \\
(0.011)\end{array}$ & $\begin{array}{c}-0.017 \\
(0.011)\end{array}$ & $\begin{array}{l}0.031^{*} \\
(0.018)\end{array}$ \\
\hline Precipitation (mm) & $\begin{array}{l}-0.025^{* * *} \\
(0.003)\end{array}$ & $\begin{array}{c}0.025^{* * *} \\
(0.004)\end{array}$ & $\begin{array}{c}0.011^{* * *} \\
(0.003)\end{array}$ & $\begin{array}{c}0.011^{* * *} \\
(0.003)\end{array}$ & $\begin{array}{c}0.021^{* * *} \\
(0.006)\end{array}$ \\
\hline Snowfall $(\mathrm{cm})$ & $\begin{array}{c}-0.035^{* * *} \\
(0.004)\end{array}$ & $\begin{array}{c}0.016^{* * *} \\
(0.004)\end{array}$ & $\begin{array}{c}0.007^{* *} \\
(0.003)\end{array}$ & $\begin{array}{l}-0.003 \\
(0.003)\end{array}$ & $\begin{array}{c}-0.014^{* *} \\
(0.006)\end{array}$ \\
\hline$\%$ days high temp $>90 \mathrm{~F}$ & $\begin{array}{c}-0.024^{* * *} \\
(0.009)\end{array}$ & $\begin{array}{l}-0.010 \\
(0.009)\end{array}$ & $\begin{array}{l}-0.013 \\
(0.009)\end{array}$ & $\begin{array}{l}-0.006 \\
(0.008)\end{array}$ & $\begin{array}{c}-0.053^{* * *} \\
(0.014)\end{array}$ \\
\hline$\%$ days low temp $<30 \mathrm{~F}$ & $\begin{array}{l}-0.024^{*} \\
(0.013)\end{array}$ & $\begin{array}{l}-0.021 \\
(0.013)\end{array}$ & $\begin{array}{c}0.006 \\
(0.013)\end{array}$ & $\begin{array}{c}0.012 \\
(0.012)\end{array}$ & $\begin{array}{l}-0.027 \\
(0.021)\end{array}$ \\
\hline $\mathrm{N}$ & 1329900 & & & & \\
\hline Counties & 3100 & & & & \\
\hline Months & 429 & & & & \\
\hline $\mathrm{R} 2$ & 0.553 & & & & \\
\hline
\end{tabular}


Table 3: Model Including Spatial Lags (Inverse-Distance)

Panel A: Own-County Effects

\begin{tabular}{|c|c|c|c|c|c|}
\hline & $\begin{array}{c}(1) \\
\text { Contemporaneous }\end{array}$ & $\begin{array}{c}(2) \\
1 \text { st lag }\end{array}$ & $\begin{array}{c}(3) \\
\text { 2nd lag }\end{array}$ & $\begin{array}{c}\text { (4) } \\
\text { 3rd lag }\end{array}$ & $\begin{array}{c}\text { (5) } \\
\text { Cumulative effect }\end{array}$ \\
\hline Avg. daily high temp - Spring & $\begin{array}{c}0.056^{* * *} \\
(0.016)\end{array}$ & $\begin{array}{c}-0.066^{* * *} \\
(0.015)\end{array}$ & $\begin{array}{l}-0.011 \\
(0.014)\end{array}$ & $\begin{array}{l}-0.005 \\
(0.013)\end{array}$ & $\begin{array}{l}-0.026 \\
(0.021)\end{array}$ \\
\hline Avg. daily high temp - Summer & $\begin{array}{c}0.007 \\
(0.019)\end{array}$ & $\begin{array}{c}-0.042^{* *} \\
(0.018)\end{array}$ & $\begin{array}{c}-0.037^{* *} \\
(0.017)\end{array}$ & $\begin{array}{l}-0.009 \\
(0.015)\end{array}$ & $\begin{array}{c}-0.081^{* * *} \\
(0.026)\end{array}$ \\
\hline Avg. daily high temp - Fall & $\begin{array}{c}0.017 \\
(0.018)\end{array}$ & $\begin{array}{l}-0.034^{*} \\
(0.019)\end{array}$ & $\begin{array}{c}-0.044^{* *} \\
(0.021)\end{array}$ & $\begin{array}{l}-0.015 \\
(0.019)\end{array}$ & $\begin{array}{c}-0.076^{* * *} \\
(0.028)\end{array}$ \\
\hline Avg. daily high temp - Winter & $\begin{array}{c}0.095^{* * *} \\
(0.018)\end{array}$ & $\begin{array}{l}-0.027 \\
(0.017)\end{array}$ & $\begin{array}{c}-0.060^{* * *} \\
(0.019)\end{array}$ & $\begin{array}{c}0.019 \\
(0.019)\end{array}$ & $\begin{array}{c}0.026 \\
(0.028)\end{array}$ \\
\hline Precipitation $(\mathrm{mm})$ & $\begin{array}{l}-0.006 \\
(0.004)\end{array}$ & $\begin{array}{l}0.011^{* *} \\
(0.004)\end{array}$ & $\begin{array}{l}0.010^{* *} \\
(0.004)\end{array}$ & $\begin{array}{c}0.005 \\
(0.004)\end{array}$ & $\begin{array}{l}0.019^{* *} \\
(0.008)\end{array}$ \\
\hline Snowfall $(\mathrm{cm})$ & $\begin{array}{c}0.003 \\
(0.004)\end{array}$ & $\begin{array}{r}-0.008^{*} \\
(0.004)\end{array}$ & $\begin{array}{l}-0.002 \\
(0.004)\end{array}$ & $\begin{array}{c}-0.005 \\
(0.004)\end{array}$ & $\begin{array}{c}-0.011^{*} \\
(0.007)\end{array}$ \\
\hline$\%$ days high temp $>90 \mathrm{~F}$ & $\begin{array}{l}-0.018^{*} \\
(0.010)\end{array}$ & $\begin{array}{c}0.000 \\
(0.011)\end{array}$ & $\begin{array}{c}0.014 \\
(0.010)\end{array}$ & $\begin{array}{l}-0.010 \\
(0.010)\end{array}$ & $\begin{array}{l}-0.015 \\
(0.016)\end{array}$ \\
\hline$\%$ days low temp $<30 \mathrm{~F}$ & $\begin{array}{c}-0.006 \\
(0.017)\end{array}$ & $\begin{array}{c}-0.001 \\
(0.017)\end{array}$ & $\begin{array}{c}-0.021 \\
(0.016)\end{array}$ & $\begin{array}{c}0.007 \\
(0.016)\end{array}$ & $\begin{array}{c}-0.022 \\
(0.027)\end{array}$ \\
\hline
\end{tabular}

Panel B: Spatial Lag Effects

\begin{tabular}{|c|c|c|c|c|c|}
\hline & $\begin{array}{c}(1) \\
\text { Contemporaneous }\end{array}$ & $\begin{array}{c}(2) \\
1 \text { st lag }\end{array}$ & $\begin{array}{c}(3) \\
\text { 2nd lag }\end{array}$ & $\begin{array}{c}(4) \\
\text { 3rd lag }\end{array}$ & $\begin{array}{c}(5) \\
\text { Cumulative effect }\end{array}$ \\
\hline Avg. daily high temp - Spring & $\begin{array}{c}0.097^{* *} \\
(0.048)\end{array}$ & $\begin{array}{c}0.043 \\
(0.044)\end{array}$ & $\begin{array}{l}-0.069 \\
(0.044)\end{array}$ & $\begin{array}{c}0.033 \\
(0.043)\end{array}$ & $\begin{array}{c}0.104 \\
(0.070)\end{array}$ \\
\hline Avg. daily high temp - Summer & $\begin{array}{c}0.251^{* * *} \\
(0.069)\end{array}$ & $\begin{array}{l}-0.007 \\
(0.059)\end{array}$ & $\begin{array}{c}0.072 \\
(0.052)\end{array}$ & $\begin{array}{l}-0.013 \\
(0.045)\end{array}$ & $\begin{array}{c}0.302^{* * *} \\
(0.087)\end{array}$ \\
\hline Avg. daily high temp - Fall & $\begin{array}{c}0.031 \\
(0.053)\end{array}$ & $\begin{array}{c}0.092 \\
(0.059)\end{array}$ & $\begin{array}{c}0.111 \\
(0.069)\end{array}$ & $\begin{array}{l}0.123^{*} \\
(0.070)\end{array}$ & $\begin{array}{c}0.357^{* * *} \\
(0.098)\end{array}$ \\
\hline Avg. daily high temp - Winter & $\begin{array}{c}-0.121^{* *} \\
(0.048)\end{array}$ & $\begin{array}{c}0.076 \\
(0.054)\end{array}$ & $\begin{array}{c}0.167^{* * *} \\
(0.055)\end{array}$ & $\begin{array}{l}-0.104^{*} \\
(0.055)\end{array}$ & $\begin{array}{c}0.018 \\
(0.093)\end{array}$ \\
\hline Precipitation (mm) & $\begin{array}{c}-0.051^{* * *} \\
(0.010)\end{array}$ & $\begin{array}{c}0.036^{* * *} \\
(0.011)\end{array}$ & $\begin{array}{c}0.004 \\
(0.011)\end{array}$ & $\begin{array}{c}0.016 \\
(0.010)\end{array}$ & $\begin{array}{c}0.005 \\
(0.019)\end{array}$ \\
\hline Snowfall (cm) & $\begin{array}{c}-0.182^{* * *} \\
(0.018)\end{array}$ & $\begin{array}{c}0.114^{* * *} \\
(0.018)\end{array}$ & $\begin{array}{c}0.043^{* * *} \\
(0.016)\end{array}$ & $\begin{array}{c}0.010 \\
(0.015)\end{array}$ & $\begin{array}{l}-0.015 \\
(0.029)\end{array}$ \\
\hline$\%$ days high temp $>90 \mathrm{~F}$ & $\begin{array}{l}-0.019 \\
(0.038)\end{array}$ & $\begin{array}{l}-0.028 \\
(0.037)\end{array}$ & $\begin{array}{c}-0.112^{* * *} \\
(0.038)\end{array}$ & $\begin{array}{c}0.023 \\
(0.038)\end{array}$ & $\begin{array}{c}-0.136^{* *} \\
(0.057)\end{array}$ \\
\hline$\%$ days low temp $<30 \mathrm{~F}$ & $\begin{array}{l}-0.058 \\
(0.073)\end{array}$ & $\begin{array}{l}-0.056 \\
(0.075)\end{array}$ & $\begin{array}{l}0.137^{*} \\
(0.070)\end{array}$ & $\begin{array}{c}-0.007 \\
(0.069)\end{array}$ & $\begin{array}{c}0.017 \\
(0.122)\end{array}$ \\
\hline $\mathrm{N}$ & 1329900 & & & & \\
\hline Counties & 3100 & & & & \\
\hline Months & 429 & & & & \\
\hline $\mathrm{R} 2$ & 0.553 & & & & \\
\hline
\end{tabular}


Table 4. Contemporaneous and Lagged Weather Effects on Nonfarm Payrolls

National Time Series Model

\begin{tabular}{|c|c|c|c|c|c|}
\hline & $\begin{array}{c}(1) \\
\text { Contemporaneous }\end{array}$ & $\begin{array}{c}(2) \\
\text { 1st lag }\end{array}$ & $\begin{array}{c}(3) \\
\text { 2nd lag }\end{array}$ & $\begin{array}{c}(4) \\
\text { 3rd lag }\end{array}$ & $\begin{array}{c}\text { (5) } \\
\text { Cumulative effect }\end{array}$ \\
\hline Avg. daily high temp - Spring & $\begin{array}{c}0.017 \\
(0.056)\end{array}$ & $\begin{array}{l}-0.040 \\
(0.054)\end{array}$ & $\begin{array}{l}-0.012 \\
(0.051)\end{array}$ & $\begin{array}{l}-0.046 \\
(0.049)\end{array}$ & $\begin{array}{l}-0.081 \\
(0.094)\end{array}$ \\
\hline Avg. daily high temp - Summer & $\begin{array}{c}0.084 \\
(0.111)\end{array}$ & $\begin{array}{l}-0.068 \\
(0.075)\end{array}$ & $\begin{array}{l}-0.048 \\
(0.060)\end{array}$ & $\begin{array}{l}-0.044 \\
(0.056)\end{array}$ & $\begin{array}{l}-0.076 \\
(0.144)\end{array}$ \\
\hline Avg. daily high temp - Fall & $\begin{array}{l}-0.027 \\
(0.059)\end{array}$ & $\begin{array}{c}0.031 \\
(0.083)\end{array}$ & $\begin{array}{l}-0.110 \\
(0.126)\end{array}$ & $\begin{array}{l}-0.066 \\
(0.109)\end{array}$ & $\begin{array}{l}-0.172 \\
(0.172)\end{array}$ \\
\hline Avg. daily high temp - Winter & $\begin{array}{c}0.007 \\
(0.050)\end{array}$ & $\begin{array}{l}-0.064 \\
(0.055)\end{array}$ & $\begin{array}{l}-0.090 \\
(0.057)\end{array}$ & $\begin{array}{l}-0.045 \\
(0.062)\end{array}$ & $\begin{array}{c}-0.192^{* *} \\
(0.096)\end{array}$ \\
\hline Precipitation $(\mathrm{mm})$ & $\begin{array}{l}-0.064 \\
(0.045)\end{array}$ & $\begin{array}{c}0.010 \\
(0.044)\end{array}$ & $\begin{array}{l}-0.062 \\
(0.046)\end{array}$ & $\begin{array}{l}-0.043 \\
(0.045)\end{array}$ & $\begin{array}{l}-0.158^{*} \\
(0.092)\end{array}$ \\
\hline Snowfall $(\mathrm{cm})$ & $\begin{array}{c}0.003 \\
(0.056)\end{array}$ & $\begin{array}{l}0.097^{*} \\
(0.054)\end{array}$ & $\begin{array}{c}0.145^{* * *} \\
(0.055)\end{array}$ & $\begin{array}{l}0.092^{*} \\
(0.054)\end{array}$ & $\begin{array}{c}0.337^{* * *} \\
(0.102)\end{array}$ \\
\hline$\%$ days high temp $>90 \mathrm{~F}$ & $\begin{array}{l}-0.032 \\
(0.105)\end{array}$ & $\begin{array}{c}0.051 \\
(0.096)\end{array}$ & $\begin{array}{c}0.167 \\
(0.119)\end{array}$ & $\begin{array}{c}0.086 \\
(0.106)\end{array}$ & $\begin{array}{c}0.273 \\
(0.183)\end{array}$ \\
\hline$\%$ days low temp $<30 \mathrm{~F}$ & $\begin{array}{l}-0.178 \\
(0.140)\end{array}$ & $\begin{array}{c}-0.288^{*} \\
(0.150)\end{array}$ & $\begin{array}{c}-0.336^{* *} \\
(0.147)\end{array}$ & $\begin{array}{c}-0.360^{* *} \\
(0.143)\end{array}$ & $\begin{array}{c}-1.162^{* * *} \\
(0.287)\end{array}$ \\
\hline $\mathrm{N}$ & 429 & & & & \\
\hline $\mathrm{R} 2$ & 0.287 & & & & \\
\hline RMSE & 0.218 & & & & \\
\hline
\end{tabular}

Table 5. In-Sample and Out-of-Sample Explanatory Power of Weather Effects for National Payroll Employment Growth

\begin{tabular}{|c|c|c|c|c|c|c|c|c|}
\hline & County Model RH & $\mathrm{R} 2$ & County Model no RH & $\mathrm{R} 2$ & County Model SL & $\mathrm{R} 2$ & National Model & $\mathrm{R} 2$ \\
\hline Backcast & $\begin{array}{c}0.457^{* *} \\
(0.238)\end{array}$ & 0.009 & $\begin{array}{c}0.414^{* *} \\
(0.225)\end{array}$ & 0.008 & $\begin{array}{c}0.091 \\
(0.099)\end{array}$ & 0.002 & $\begin{array}{c}1.000^{* * *} \\
(0.144)\end{array}$ & 0.102 \\
\hline Nowcast & $\begin{array}{c}0.899^{* * *} \\
(0.345)\end{array}$ & 0.043 & $\begin{array}{c}0.847^{* * *} \\
(0.328)\end{array}$ & 0.043 & $\begin{array}{l}0.248^{* *} \\
(0.141)\end{array}$ & 0.020 & $\begin{array}{c}0.233 \\
(0.177)\end{array}$ & 0.011 \\
\hline
\end{tabular}

Notes: ${ }^{* *} p<0.01,{ }^{* *} p<0.05,{ }^{*} p<0.10$. Employment Growth is private nonfarm employment growth from the BLS CES payroll survey. For the backcast results, both the model estimation and fit evaluation use data from $1980 \mathrm{~m} 1$ to $2015 \mathrm{~m} 12$. For the nowcast results, models are estimated iteratively with first month fixed at $1980 \mathrm{~m} 1$ and last month iterated from $2003 \mathrm{~m} 5$ to $2015 \mathrm{~m} 12$ for county models and from $2003 \mathrm{~m} 12$ to $2016 \mathrm{~m} 7$ for national model. The fitted models are then used to predict weather effects 8 months out of sample for county models (inline with the 8 month QCEW data lag) and 1 month out of sample for national model (inline with the 1 month CES data lag). County weather effects are then aggregated to national level. This process results in a time series, for each model, of national weather effect nowcasts from $2004 \mathrm{~m} 1$ to $2016 \mathrm{~m} 8$. The table shows the slope coefficient, standard error (in parentheses), and $R^{2}$ from bivariate regressions of each model's national weather effect estimates on payroll employment growth from $2004 \mathrm{~m} 1$ to $2016 \mathrm{~m} 8$. See text for further details. 
Table 6. Out-of-Sample Explanatory Power of Weather Effects for Various National Labor Market Outcomes

\begin{tabular}{|c|c|c|c|c|c|}
\hline & County Model (RH) & $\mathrm{R} 2$ & National Model & $\mathrm{R} 2$ & GW test \\
\hline Employment Growth, Private Nonfarm, Payroll Survey & $\begin{array}{c}0.899^{* * *} \\
(0.345)\end{array}$ & 0.043 & $\begin{array}{c}0.233 \\
(0.177\end{array}$ & 0.011 & 0.201 \\
\hline Employment Growth, Private Nonfarm, QCEW (SA) & $\begin{array}{c}1.041^{* * *} \\
(0.437)\end{array}$ & 0.037 & $\begin{array}{l}0.200 \\
(0.224)\end{array}$ & 0.005 & 0.258 \\
\hline Vacancy Rate (monthly change) & $\begin{array}{c}0.712^{* * *} \\
(0.295)\end{array}$ & 0.037 & $\begin{array}{l}0.138 \\
(0.151)\end{array}$ & 0.006 & 0.228 \\
\hline Hires Rate (monthly change) & $\begin{array}{c}0.862^{* * *} \\
(0.244)\end{array}$ & 0.077 & $\begin{array}{c}0.076 \\
(0.128)\end{array}$ & 0.002 & 0.164 \\
\hline Quits Rate (monthly change) & $\begin{array}{c}0.222 \\
(0.174)\end{array}$ & 0.011 & $\begin{array}{c}0.000 \\
(0.088)\end{array}$ & 0.000 & 0.574 \\
\hline Employment Growth, less than 50 employees & $\begin{array}{c}1.059^{* * *} \\
(0.485)\end{array}$ & 0.050 & $\begin{array}{c}0.572 \\
(0.295)\end{array}$ & 0.042 & 0.900 \\
\hline Employment Growth, 50 to 499 employees & $\begin{array}{c}0.869 \\
(0.616)\end{array}$ & 0.026 & $\begin{array}{c}0.854 \\
(0.367)\end{array}$ & 0.060 & 0.617 \\
\hline Employment Growth, 500 or more employees & $\begin{array}{c}0.567 \\
(0.504)\end{array}$ & 0.020 & $\begin{array}{c}0.681^{* * *} \\
(0.299)\end{array}$ & 0.058 & 0.552 \\
\hline Weather Absences Rate (monthly change) & $\begin{array}{c}-0.683^{* * * *} \\
(0.161)\end{array}$ & 0.107 & $\begin{array}{c}0.017 \\
(0.086)\end{array}$ & 0.000 & 0.174 \\
\hline Non-weather Absences Rate (monthly change) & $\begin{array}{c}0.100 \\
(2.131)\end{array}$ & 0.000 & $\begin{array}{l}-1.449 \\
(1.065)\end{array}$ & 0.012 & 0.500 \\
\hline
\end{tabular}

Notes: ${ }^{* * *} p<0.01,{ }^{* *} p<0.05,{ }^{*} p<0.10$. Standard errors in parentheses. Model is estimated iteratively with first month fixed at $1980 \mathrm{~m} 1$ and last month iterated from $2003 \mathrm{~m} 5$ to $2015 \mathrm{~m} 12$ for county models and from $2003 \mathrm{~m} 12$ to $2016 \mathrm{~m} 7$ for national model. The fitted models are then used to predict weather effects 8 months out of sample for county models (inline with the 8 month QCEW data lag) and 1 month out of sample for national model (inline with the 1 month CES data lag). County weather effects are then aggregated to national level. This process results in a time series, for each model, of national weather effect nowcasts from $2004 \mathrm{~m} 1$ to $2016 \mathrm{~m} 8$. The table shows the slope coefficient, standard error (in parentheses), and $R^{2}$ from separate bivariate regressions of each model's national weather effect estimates on each of the indicated variables from $2004 \mathrm{~m} 1$ to $2016 \mathrm{~m} 8$. See text for further details. 
Table 7: Weather Effects and Asset Price Responses on Employment Report Release Days

Panel A: Full Sample

\begin{tabular}{|c|c|c|c|c|c|c|c|}
\hline & $\begin{array}{c}(1) \\
\text { County no RH }\end{array}$ & $\begin{array}{l}(2) \\
R^{2} \\
\end{array}$ & $\begin{array}{c}(3) \\
\text { County RH } \\
\end{array}$ & $\begin{array}{l}(4) \\
R^{2}\end{array}$ & $\begin{array}{c}(5) \\
\text { Payroll surprise } \\
\end{array}$ & $\begin{array}{l}(6) \\
R^{2}\end{array}$ & $\begin{array}{l}(7) \\
\mathrm{N}\end{array}$ \\
\hline Real-Time Surprise in Payroll Employment Growth & $\begin{array}{c}.527 * * * \\
(.094)\end{array}$ & .091 & $\begin{array}{c}589^{* * * *} \\
(.099)\end{array}$ & .103 & & & 313 \\
\hline S\&P 500 daily return & $\begin{array}{c}3.013^{* *} \\
(1.482)\end{array}$ & 013 & $\begin{array}{c}2.223 \\
(1.569)\end{array}$ & .007 & $\begin{array}{l}-.338 \\
(.825)\end{array}$ & .001 & 306 \\
\hline Dow Jones Ind. Avg daily return & $\begin{array}{c}3.618^{* * * *} \\
(1.389)\end{array}$ & .022 & $\begin{array}{c}2.921^{* *} \\
(1.473)\end{array}$ & .013 & $\begin{array}{l}.635 \\
(.775)\end{array}$ & .002 & 306 \\
\hline 3-month Treasury Bond daily change & $\begin{array}{c}.246^{* * *} \\
(.067)\end{array}$ & .041 & $\begin{array}{c}.273^{* * *} \\
(.071)\end{array}$ & .046 & $\begin{array}{l}.321 * * * \\
(.034)\end{array}$ & .216 & 313 \\
\hline 1-year Treasury Bond daily change & $\begin{array}{c}.357^{* * * *} \\
(.092)\end{array}$ & .046 & $\begin{array}{c}.416^{* * *} \\
(.097)\end{array}$ & .056 & $\begin{array}{l}.581 * * * \\
(.042)\end{array}$ & .372 & 313 \\
\hline 2-year Treasury Bond daily change & $\begin{array}{l}.529 * * * \\
(.115)\end{array}$ & .063 & $\begin{array}{c}.609^{* * * *} \\
(.12)\end{array}$ & .076 & $\begin{array}{l}.71 * * * \\
(.054)\end{array}$ & .349 & 313 \\
\hline 5-year Treasury Bond daily change & $\begin{array}{c}.581^{* * * *} \\
(.122)\end{array}$ & .068 & $\begin{array}{c}.669^{* * * *} \\
(.127)\end{array}$ & .082 & $\begin{array}{c}.681 * * * \\
(.06)\end{array}$ & .285 & 313 \\
\hline 10-year Treasury Bond daily change & $\begin{array}{c}.494^{* * * *} \\
(.107)\end{array}$ & .064 & $\begin{array}{c}.567^{* * * *} \\
(.112)\end{array}$ & .076 & $\begin{array}{l}.536^{* * * *} \\
(.055)\end{array}$ & .229 & 313 \\
\hline 30-year Treasury Bond daily change & $\begin{array}{c}.455^{* * *} \\
(.099)\end{array}$ & .075 & $\begin{array}{c}.531^{* * *} \\
(.104)\end{array}$ & .09 & $\begin{array}{c}.386 * * * \\
(.051)\end{array}$ & .173 & 265 \\
\hline
\end{tabular}

Standard errors in parentheses

${ }^{*} p<0.1,{ }^{* *} p<0.05,{ }^{* * *} p<0.01$

Panel B: Rolling Out-of-Sample

\begin{tabular}{|c|c|c|c|c|c|c|c|}
\hline & $\begin{array}{c}\text { (1) } \\
\text { County no RH }\end{array}$ & $\begin{array}{l}(2) \\
R^{2} \\
\end{array}$ & $\begin{array}{c}(3) \\
\text { County RH }\end{array}$ & $\begin{array}{l}(4) \\
R^{2} \\
\end{array}$ & $\begin{array}{c}(5) \\
\text { Payroll surprise }\end{array}$ & $\begin{array}{l}6) \\
R^{2} \\
\end{array}$ & $\begin{array}{l}(7) \\
\mathrm{N}\end{array}$ \\
\hline Real-Time Surprise in Payroll Employment Growth & $\begin{array}{c}.375^{* * *} \\
(.077)\end{array}$ & .136 & $\begin{array}{c}.422^{* * *} \\
(.081)\end{array}$ & .155 & & & 152 \\
\hline S\&P 500 daily return & $\begin{array}{l}3.075^{*} \\
(1.838)\end{array}$ & .019 & $\begin{array}{l}3.276^{*} \\
(1.912)\end{array}$ & .02 & $\begin{array}{c}3.432^{*} \\
(1.761)\end{array}$ & .025 & 148 \\
\hline Dow Jones Ind. Avg daily return & $\begin{array}{l}3.223^{*} \\
(1.703)\end{array}$ & .024 & $\begin{array}{l}3.307^{*} \\
(1.773)\end{array}$ & .023 & $\begin{array}{c}3.937^{* *} \\
(1.625)\end{array}$ & .039 & 148 \\
\hline 3-month Treasury Bond daily change & $\begin{array}{l}-.004 \\
(.056)\end{array}$ & 0 & $\begin{array}{l}.013 \\
(.059)\end{array}$ & 0 & $\begin{array}{l}.104^{*} \\
(.055)\end{array}$ & .023 & 152 \\
\hline 1-year Treasury Bond daily change & $\begin{array}{l}.064 \\
(.075)\end{array}$ & .005 & $\begin{array}{l}.14^{*} \\
(.079)\end{array}$ & .021 & $\begin{array}{c}.483^{* * *} * \\
(.063)\end{array}$ & .283 & 152 \\
\hline 2-year Treasury Bond daily change & $\begin{array}{l}.27^{* *} \\
(.121)\end{array}$ & .032 & $\begin{array}{c}.366^{* * *} \\
(.127)\end{array}$ & .053 & $\begin{array}{c}.817 * * * \\
(.101)\end{array}$ & .302 & 152 \\
\hline 5-year Treasury Bond daily change & $\begin{array}{c}.377^{* * *} * \\
(.143)\end{array}$ & .044 & $\begin{array}{c}.465 * * * \\
(.15)\end{array}$ & .061 & $\begin{array}{c}.982^{* * *} * \\
(.119)\end{array}$ & .311 & 152 \\
\hline 10-year Treasury Bond daily change & $\begin{array}{l}.323^{* *} \\
(.126)\end{array}$ & .042 & $\begin{array}{c}.382^{* * *} \\
(.132)\end{array}$ & .053 & $\begin{array}{c}.812^{* * *} \\
(.108)\end{array}$ & .274 & 152 \\
\hline 30-year Treasury Bond daily change & $\begin{array}{l}.243^{*} \\
(.123)\end{array}$ & .03 & $\begin{array}{l}.269^{* *} \\
(.132)\end{array}$ & .032 & $\begin{array}{l}.62^{* * *} \\
(.115)\end{array}$ & .19 & 127 \\
\hline
\end{tabular}

Standard errors in parentheses

${ }^{*} p<0.1,{ }^{* *} p<0.05,{ }^{* * *} p<0.01$

Notes: In Panel A, the county model is estimated over $1980 \mathrm{~m} 1$ to $2015 \mathrm{~m} 12$. County weather effects are obtained from the fitted model and aggregated to the national level. The regressions in Panel A use a sample from $1989 \mathrm{~m} 12$ (the earliest month of the payroll surprise data) to $2016 \mathrm{~m} 8$. In Panel B, each model (county DPD model with or without regional heterogeneity) is estimated iteratively with first month fixed at $1980 \mathrm{~m} 1$ and last month iterated from $2003 \mathrm{~m} 5$ to $2015 \mathrm{~m} 12$. The fitted models are then used to predict weather effects 8 months out of sample (inline with the 8 month QCEW data lag). County weather effects are then aggregated to national level. This process results in a time series, for each model, of national weather effect nowcasts from $2004 \mathrm{~m} 1$ to $2016 \mathrm{~m} 8$. The table shows the slope coefficient, standard error (in parentheses), and $R^{2}$ from separate bivariate regressions of each model's nowcasts on each of the indicated variables from $2004 \mathrm{~m} 1$ to $2016 \mathrm{~m} 8$. The financial market variables are changes (or returns) from the market close of the prior day to the market close of the day of the employment report. See text for further details. 
Table 8. Mean Daily Stock Returns and Treasury Yield Changes

Various Subsamples

\begin{tabular}{|c|c|c|c|c|}
\hline & $\begin{array}{l}\text { All Days } \\
(1 / 1 / 2004 \text { to } \\
8 / 31 / 2016)\end{array}$ & All Release Days & $\begin{array}{c}\text { Release Days, } \\
\text { Nowcast }>0\end{array}$ & $\begin{array}{c}\text { Release Days, } \\
\text { Nowcast }<0\end{array}$ \\
\hline Payroll Surprises (\%) & -- & -0.78 & 0.87 & -2.29 \\
\hline S\&P $500(\%)$ & 0.02 & 0.02 & 0.21 & -0.14 \\
\hline Dow Jones (\%) & 0.02 & 0.02 & 0.21 & -0.15 \\
\hline 1-yr Treasury (bps) & -0.01 & -0.03 & 0.72 & -0.64 \\
\hline 2-yr Treasury (bps) & -0.02 & 0.26 & 2.50 & -1.64 \\
\hline 5-yr Treasury (bps) & -0.04 & 0.17 & 2.95 & -2.21 \\
\hline 10-yr Treasury (bps) & -0.06 & 0.32 & 2.57 & -1.57 \\
\hline 30-yr Treasury (bps) & -0.05 & 0.81 & 2.14 & -0.41 \\
\hline
\end{tabular}

Notes: The payroll employment surprise and stock returns are in percentage points; Treasury yield changes are in basis points. See text for details. 
Figure 1. Relationship between Weather Effect and Financial Markets on Employment Report Release Days

(Bin-scatter plots)

Backcasts
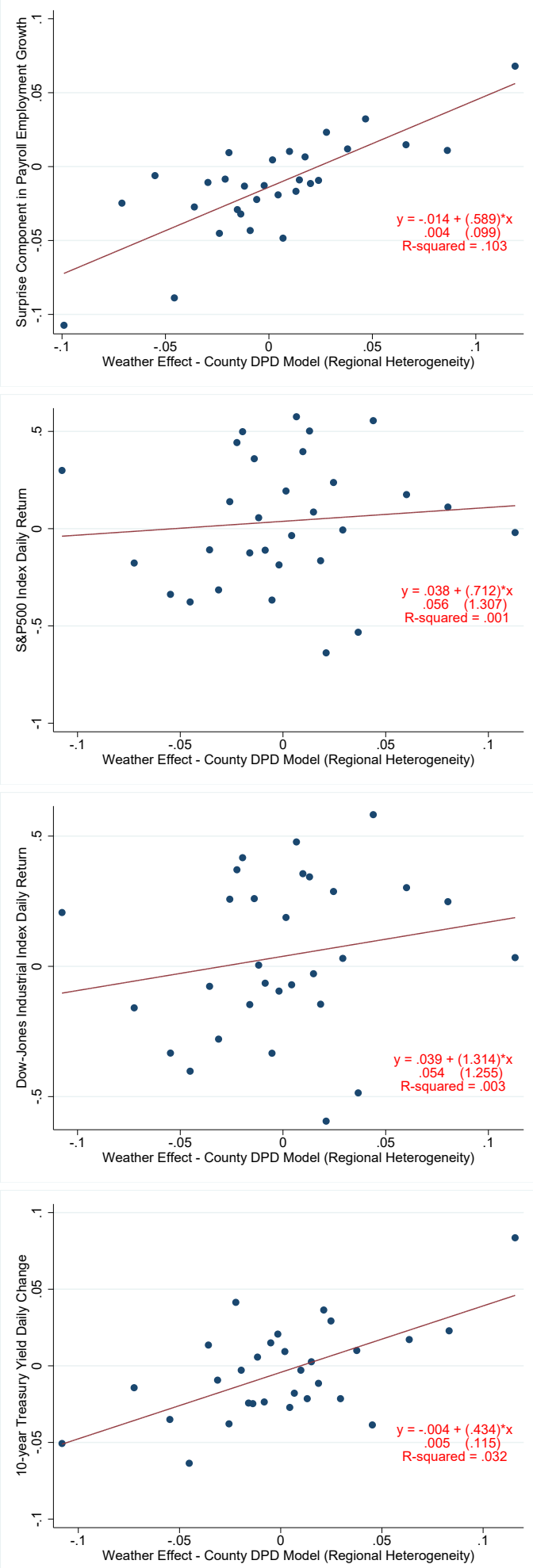

Nowcasts
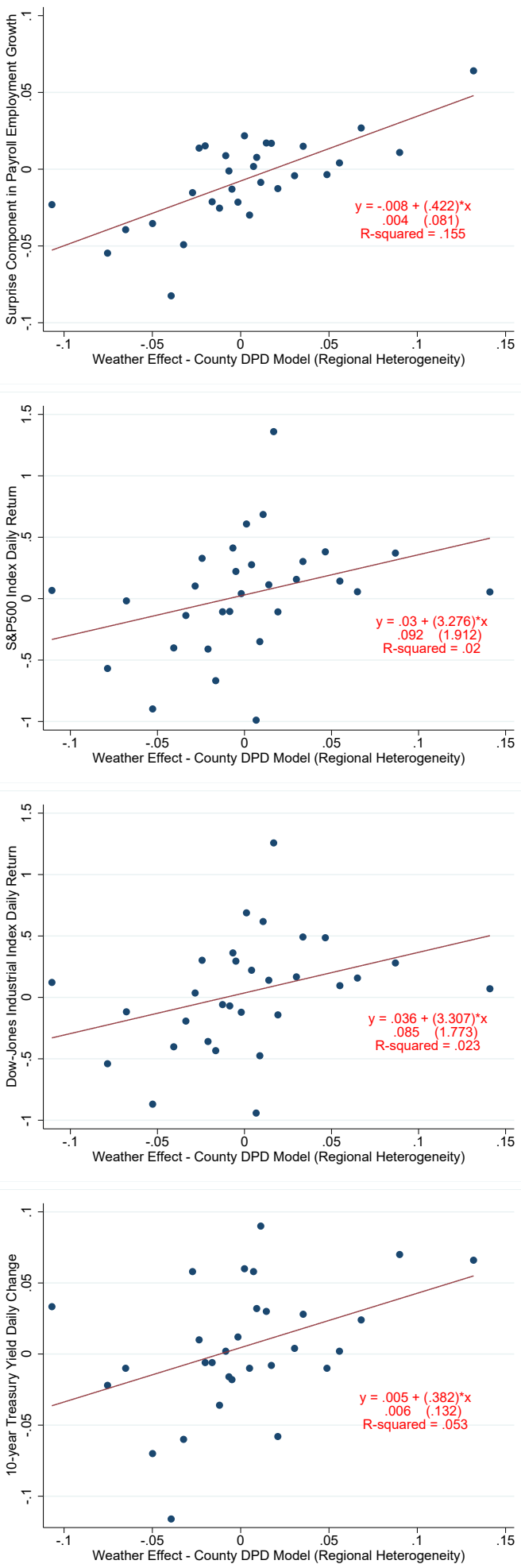

Notes: Each panel contains a bin-scatter plot showing the relationship between the indicated outcome variable (y-axis) and the national employment weather effect estimate ( $\mathrm{x}$-axis). Each point shows the mean $\mathrm{x}$ and $\mathrm{y}$ values within a bin. Bins are defined according to 30 quantiles of the $\mathrm{x}$ variable. The shown fit line is based on a linear regression of the outcome variable on the national employment weather effect, using the raw data (not the binned data). The weather effect estimate is derived from aggregating county-level weather effects, estimated using the county DPD model without regional heterogeneity. The left-side panels use weather effect estimates for which the county model is estimated using the full $1980 \mathrm{~m} 1$ - 2016m8 sample; the right-side panels use estimates for which the county model is estimated using rolling (expanding-window) samples ending eight months prior to the observation month. See text for details. 
Figure 2. Performance of Simple Trading Strategy Based on Weather Effect Nowcasts
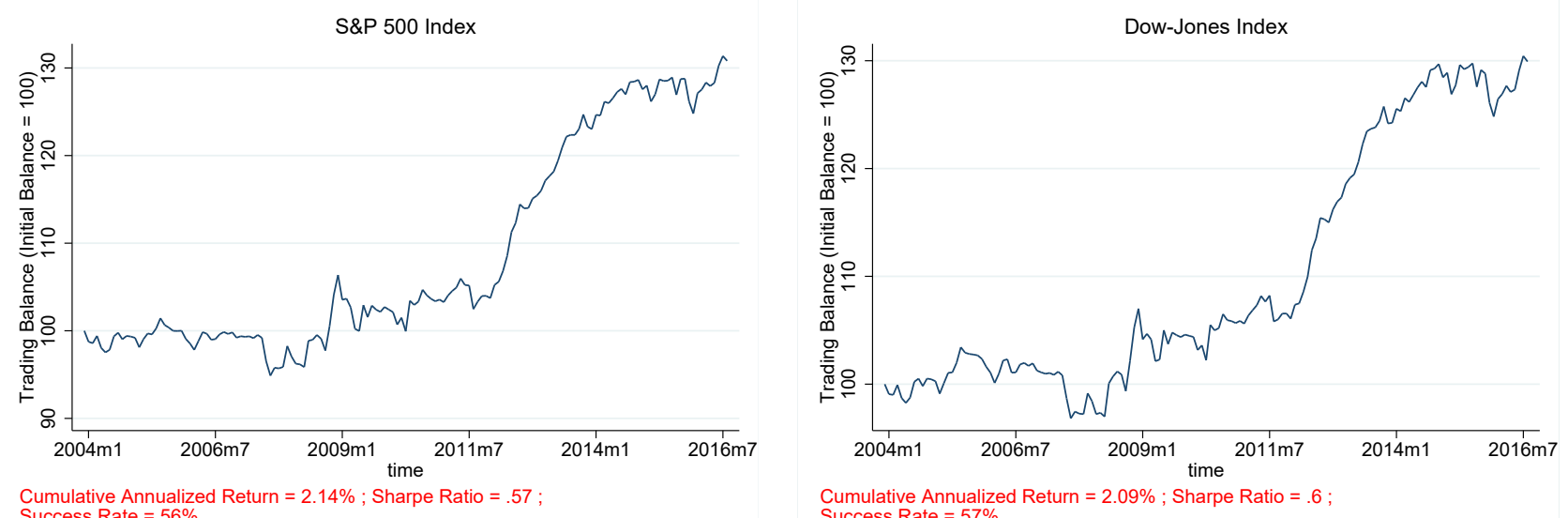
Success Rate $=56 \%$

Cumulative Annualized Return $=2.09 \% ;$ Sharpe Ratio $=.6$; Success Rate $=57 \%$
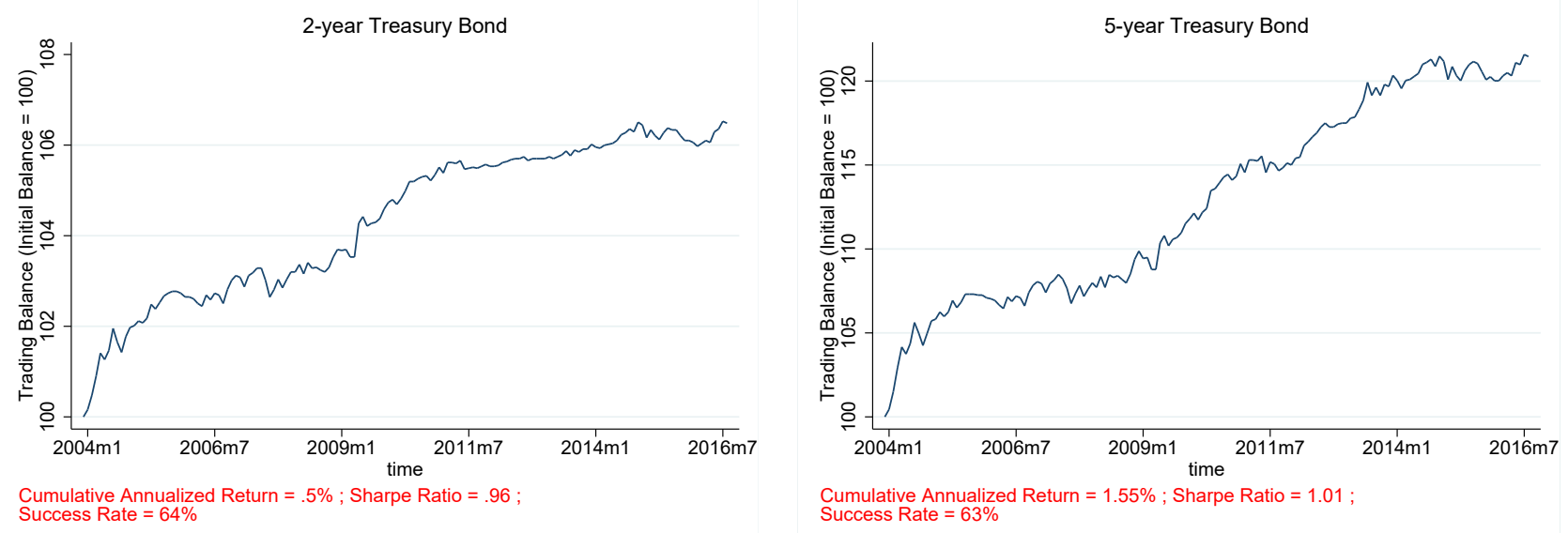
Cumulative Annualized Return $=1.55 \% ;$ Sharpe Ratio $=1.01$
Success Rate $=63 \%$ Success Rate $=64 \%$
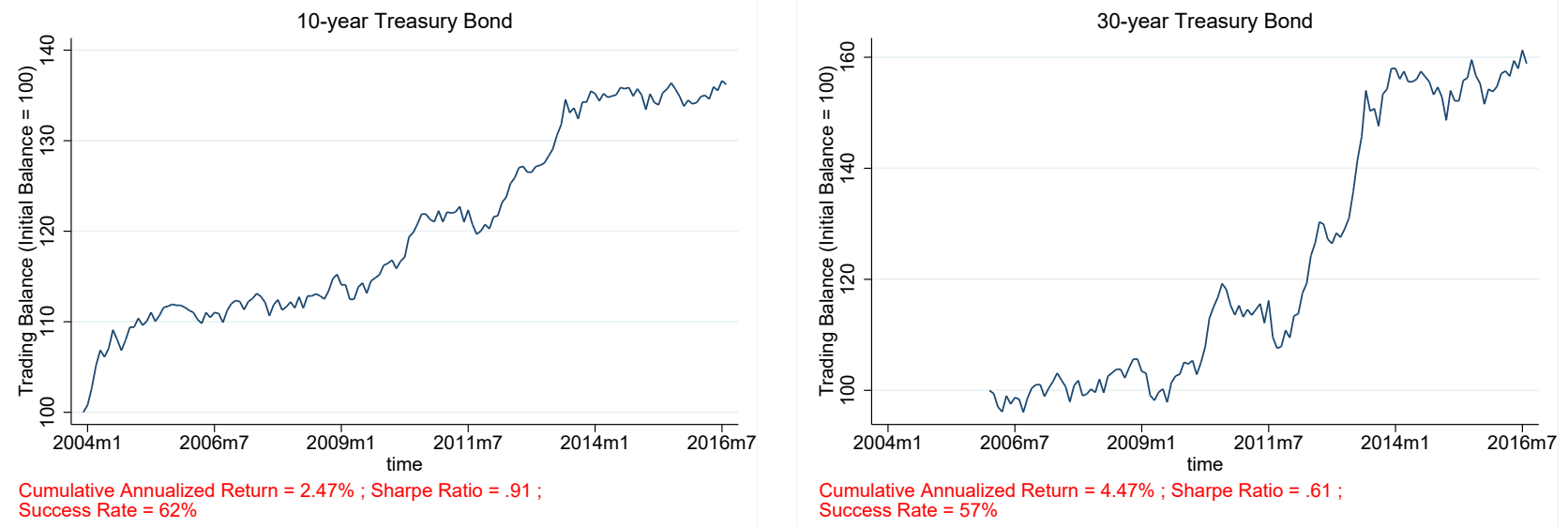

Notes: Each panel shows the evolution of an investment balance, with an initial value of 100 in $2003 \mathrm{~m} 12$, from following a simple trading strategy based on the weather effect nowcasts applied to the indicated asset type. Below each chart, the cumulative annualized return and the success rate (percentage of trades yielding a positive daily return) over the entire period are shown. The trading rule is as follows: when the weather effect nowcast is positive, at the end of the day before the employment report take a long position in stocks or a short position in bonds; when the nowcast is negative, do the opposite. Positions are closed out at the end of the day of the report and held in cash until the day before the next employment report. See text for details. 